\title{
The Influence of Multivesicular Release and Postsynaptic Receptor Saturation on Transmission at Granule Cell to Purkinje Cell Synapses
}

\author{
Kelly A. Foster, ${ }^{\star}$ John J. Crowley, ${ }^{\star}$ and Wade G. Regehr \\ Department of Neurobiology, Harvard Medical School, Boston, Massachusetts 02115
}

\begin{abstract}
The properties of a synapse are crucially dependent on whether an action potential can trigger the release of multiple vesicles at an individual release site [multivesicular release (MVR)] and whether fusion of a single vesicle leads to receptor saturation. MVR and receptor saturation both occur at some high $p$ synapses, but it is not known whether they also occur at low $p$ synapses. Here we examine this issue at the low $p$ synapse between parallel fibers and Purkinje cells using the low-affinity antagonist DGG ( $\gamma$-D-glutamylglycine) to relieve AMPA receptor saturation. We find that the presence of MVR and receptor saturation at this synapse alters the calcium dependence of synaptic transmission and reduces the extent of facilitation. These findings establish that MVR and postsynaptic receptor saturation can influence transmission even at synapses with a low initial probability of release and suggest that these properties may be common at synapses in the mammalian brain.
\end{abstract}

Key words: synaptic plasticity; cerebellum; saturation; multivesicular release; facilitation; calcium dependence; parallel fiber; low-affinity antagonist

\section{Introduction}

The amount of neurotransmitter that is released at a synapse in response to a single action potential can have important consequences for synaptic function and plasticity. At some types of synapses, it appears that an action potential can trigger the release of at most a single vesicle at an individual release site (Korn et al., 1982; Stevens and Wang, 1995; Dobrunz et al., 1997; Silver et al., 2003; Murphy et al., 2004; Biro et al., 2005). This observation, combined with the presence of multiple docked vesicles at each release site (Atwood and Karunanithi, 2002; Xu-Friedman and Regehr, 2004), led to the hypothesis that a mechanism must exist to prevent the fusion of multiple vesicles at an individual release site (Triller and Korn, 1982; Korn et al., 1984; Stevens, 1993). However, at other synapses, an action potential can evoke the release of multiple vesicles at a single release site [multivesicular release (MVR)]. This is well established for climbing fiber (CF) to Purkinje cell synapses (Wadiche and Jahr, 2001) and inhibitory synapses that have a high initial probability of release $(p)$ (Auger et al., 1998; Kirischuk et al., 1999), for the hair cell synapse (Glowatzki and Fuchs, 2002) and for ribbon synapses onto AII amacrine cells (Singer et al., 2004). However, it remains controversial

Received Sept. 22, 2005; revised 0ct. 28, 2005; accepted 0ct. 29, 2005.

This work was supported by National Institutes of Health Grant R01-NS32405. We thank Michael Beierlein, Aaron

Best, Dawn Blitz, Stephan Brenowitz, Patrick Safo, and Megan Carey for their comments on this manuscript.

${ }^{*}$ K.A.F. and J.J.C. contributed equally to this work.

Correspondence should be addressed to Wade Regehr, Department of Neurobiology, Harvard Medical School, 220 Longwood Avenue, Goldenson 308, Boston, MA 02115. E-mail: wade_regehr@hms.harvard.edu.

K. A. Foster's present address: Massachusetts Institute of Technology, 77 Massachusetts Avenue, E18-211, Cambridge, MA 02139.

DOI:10.1523/JNEUROSCI.4029-05.2005

Copyright $\odot 2005$ Society for Neuroscience 0270-6474/05/2511655-11\$15.00/0 whether MVR occurs at synapses with moderate to low $p$ such as excitatory synapses in the hippocampus (Tong and Jahr, 1994; Stevens and Wang, 1995; Abenavoli et al., 2002; Oertner et al., 2002; Conti and Lisman, 2003).

A related issue is whether the neurotransmitter liberated by a single action potential is sufficient to occupy a large fraction of receptors at a single postsynaptic density (PSD). If so, then postsynaptic receptors are partially "saturated," and fusion of additional vesicles at the same release site produces only a small incremental increase in the response. At the climbing fiber to Purkinje cell synapse (CF synapse), both MVR and postsynaptic receptor saturation occur and have profound effects on usedependent synaptic plasticity (Wadiche and Jahr, 2001; Foster et al., 2002; Harrison and Jahr, 2003; Foster and Regehr, 2004). However, it remains an open question whether this is a specialization that is only important at $\mathrm{CF}$ synapses and some inhibitory synapses (Auger et al., 1998). Of particular interest is whether MVR and AMPA receptor (AMPAR) saturation influence the properties of synapses with a low initial $p$ and if so what the consequences are.

Here we examine the contribution of MVR and postsynaptic receptor saturation to release at the synapse between granule cell parallel fibers (PFs) and Purkinje cells (PF synapse). This synapse is well suited to these studies because it has a low initial $p$ (Dittman et al., 2000), exhibits prominent paired-pulse facilitation (Konnerth et al., 1990; Perkel et al., 1990), has on average seven docked vesicles per release site, and each synapse is isolated from neighboring synapses by glia ensheathment (Xu-Friedman et al., 2001). In a manner similar to that used previously at the CF synapse (Wadiche and Jahr, 2001), we used the low-affinity AMPA receptor antagonist $\gamma$-D-glutamylglycine (DGG) 
(Watkins et al., 1990; Liu et al., 1999) to relieve saturation. The use of low-affinity antagonists (Clements et al., 1992) such as DGG relies on their rapid kinetics, which allows them to compete with glutamate for binding sites on the AMPA receptor. This greatly lowers the extent to which glutamate binds to postsynaptic receptors and relieves the effects of saturation. In previous studies of long-term plasticity at PF synapses, it was shown that DGG can have small effects on paired-pulse plasticity (Coesmans et al., 2004; Sims and Hartell, 2005). Here we use DGG to show that MVR and receptor saturation can be prominent at the PF synapse, particularly when facilitation increases $p$. These studies are consistent with the view that MVR is a widespread feature of both high and low $p$ synapses throughout the brain. At the PF synapse, MVR is particularly prominent when facilitation increases $p$.

\section{Materials and Methods}

Transverse slices ( $250 \mu \mathrm{m}$ thick) were cut from the cerebellar vermis of 12- to 15-d-old Sprague Dawley rats as described previously (Atluri and Regehr, 1998). Slices were superfused at $1 \mathrm{ml} / \mathrm{min}$ with a saline solution consisting of the following (in mM): $125 \mathrm{NaCl}, 2.5 \mathrm{KCl}, 2 \mathrm{CaCl}_{2}, 1 \mathrm{MgCl}_{2}$, $26 \mathrm{NaHCO}_{3}, 1.25 \mathrm{NaH}_{2} \mathrm{PO}_{4}$, and 25 glucose (bubbled with $95 \% \mathrm{O}_{2} / 5 \%$ $\mathrm{CO}_{2}$ unless otherwise mentioned). In experiments in which $\mathrm{CaCl}_{2}$ was varied, the concentration of $\mathrm{MgCl}_{2}$ was also changed to maintain the concentration of divalent cations, such that $3 \mathrm{Ca}_{\mathrm{e}}$ corresponds to $3 \mathrm{CaCl}_{2}$ and $0 \mathrm{MgCl}_{2}, 2 \mathrm{Ca}_{\mathrm{e}}$ corresponds to $2 \mathrm{CaCl}_{2}$ and $1 \mathrm{MgCl}_{2}$, and $1 \mathrm{Ca}_{\mathrm{e}}$ corresponds to $1 \mathrm{CaCl}_{2}$ and $2 \mathrm{MgCl}_{2}$. Experiments were performed at room temperature unless otherwise noted. Bicuculline at $20 \mu \mathrm{M}$ (Sigma, St. Louis, MO) was included in the external solution to block $\mathrm{GABA}_{\mathrm{A}^{-}}$ mediated synaptic currents.

Whole-cell recordings of Purkinje cells were obtained as described previously (Regehr and Mintz, 1994), with an internal solution consisting of the following (in mM): $35 \mathrm{CsF}, 100 \mathrm{CsCl}, 10$ EGTA, 10 HEPES, and $0.2 \mathrm{D} 600$ (methoxyverapamil), adjusted to $\mathrm{pH} 7.2$ with CsOH. D600 was included to block L-type voltage-gated calcium channels. The access resistance and leak current ( -20 to $-200 \mathrm{pA}$ holding at $-40 \mathrm{mV}$ ) were monitored continuously, and experiments were rejected if either of these parameters increased significantly during the recording. Parallel fibers were stimulated by placing a glass electrode filled with external saline in the molecular layer several hundred micrometers from the recording electrode. In all experiments, presynaptic volleys were monitored as a measure of the number of activated fibers (Sabatini and Regehr, 1997). We found that the extent of paired-pulse facilitation depended on the position of the stimulus electrode within the molecular layer. In the presence of $3 \mathrm{mM} \mathrm{Ca}_{\mathrm{e}}$, facilitation tended to be more prominent in proximal synapses $(0.99 \pm 0.10 ; n=9)$ than in distal synapses $(0.36 \pm 0.06$; $n=6$ ). To reduce the variability in synaptic responses, in our experiments the stimulus electrode was placed $\sim 25-50 \mu \mathrm{m}$ from the Purkinje cell layer for molecular layer stimulation. In experiments in which $\mathrm{Ca}_{\mathrm{e}}$ was altered, the amplitude of the volley changed by $<10 \%$. Evoked EPSCs were recorded at a holding potential of $-40 \mathrm{mV}$ to inactivate $\mathrm{Na}^{+}$ and $\mathrm{Ca}^{2+}$ currents using $0.8-1.2 \mathrm{M} \Omega$ glass electrodes.

For granule cell stimulation experiments (see Fig. 3), a pair of glass electrodes filled with external saline separated by $10-40 \mu \mathrm{m}$ was placed in the granule cell layer of the transverse slice, $\sim 100 \mu \mathrm{m}$ lateral to the recorded Purkinje cell. This configuration allows a spatially dispersed set of parallel fiber synapses to be activated, with minimal contribution of synapses formed by the ascending branch of the granule cell axons (Marcaggi et al., 2003; Sims and Hartell, 2005). Granular layer stimulation likely activated proximal and distal synapses, and thus facilitation for granular layer stimulation was intermediate between facilitation observed for proximal and distal molecular layer stimulation. CPP [3-((R)2-carboxypiperazin-4-yl)propyl] at $5 \mu \mathrm{M}$ was added to the external saline to reduce the tendency of granule cells to fire in bursts. Pairs of stimuli were delivered $50 \mathrm{~ms}$ apart, every $15 \mathrm{~s}$. The position of the electrodes and the stimulus intensity were adjusted to minimize asynchronous EPSCs.

Synaptically evoked transporter currents (STCs) were recorded as de- scribed previously (Zerangue and Kavanaugh, 1996; Bergles et al., 1997; Auger and Attwell, 2000; Wadiche and Jahr, 2001). The holding potential was $-70 \mathrm{mV}$, and the internal solution consisted of the following (in mM): $135 \mathrm{~K}$-gluconate, 10 EGTA, and 10 HEPES, pH 7.3. Parallel fibers were stimulated to evoke large AMPA-mediated EPSCs, after which $25 \mu \mathrm{M}$ 2,3-dihydroxy-6-nitro-7-sulfonyl-benzo[f] quinoxaline (NBQX) and $100 \mu \mathrm{M}$ CPCCOEt [7-(hydroxy-imino)cyclopropachromen-1acarboxylate ethyl ester] were added to the external saline to block AMPA receptors and metabotropic glutamate receptors (mGluR1), respectively. The remaining current reflects the uptake of $3 \mathrm{Na}^{+}, 1 \mathrm{H}^{+}$, and 1 glutamate and the extrusion of $1 \mathrm{~K}^{+}$, from the synaptic cleft by excitatory amino acid transporters on the Purkinje cell. To confirm this, a competitive, nontransportable blocker of the excitatory amino acid transporters [DL-threo-h-benzyloxyaspartate (DL-TBOA), $300 \mu \mathrm{M}$ ] was applied at the end of each experiment.

Outputs from the Axopatch 200A amplifier (Axon Instruments, Union City, CA) were digitized with a 16 bit digital-to-analog converter (InstruTech, Great Neck, NY), with Pulse Control software (Herrington and Bookman, 1995). EPSCs were filtered at $1 \mathrm{kHz}$ with a four-pole Bessel filter. Analysis was performed using Igor Pro software (WaveMetrics, Lake Oswego, OR).

\section{Results}

\section{Properties of transmission at PF synapses}

MVR and AMPAR saturation could potentially influence several aspects of transmission at the parallel fiber to Purkinje cell synapse (PF synapse). As at many other synapses, the properties of facilitation at the PF synapse are highly sensitive to $\mathrm{Ca}_{\mathrm{e}}$. This is shown for a representative experiment in which paired-pulse facilitation is evoked by stimuli separated by $20 \mathrm{~ms}$ (Fig. $1 \mathrm{a}$ ). In this example, in $1 \mathrm{mM} \mathrm{Ca}_{\mathrm{e}}$, the half-decay time of the first EPSC is slightly faster than the second (Fig. $1 a$, left, $3.1 \mathrm{vs} 3.9 \mathrm{~ms}$ ), and in $2.5 \mathrm{mM} \mathrm{Ca}_{\mathrm{e}}$, the difference in the half-decay times of the first and second EPSCs was more pronounced (Fig. 1a, right, 3.8 vs 5.8 $\mathrm{ms})$. Such a prolongation of $\mathrm{EPSC}_{2}$ suggests that postsynaptic receptors are exposed to higher levels of glutamate for $\mathrm{EPSC}_{2}$ than for $\mathrm{EPSC}_{1}$. One possible explanation is that there is only partial vesicle fusion in response to the first EPSC and more complete fusion in response to the second EPSC. The observation that quantal size remains constant during facilitation at single hippocampal synapses (Chen et al., 2004) indicates that it is unlikely that a change in the extent of vesicle fusion contributes to an increase in glutamate levels for the second EPSC. This suggests either glutamate pooling and spillover (Carter and Regehr, 2000; Marcaggi et al., 2003; Xu-Friedman and Regehr, 2004) or that MVR and AMPAR saturation (Wadiche and Jahr, 2001) occur for facilitated transmission in high $\mathrm{Ca}_{\mathrm{e}}$.

Increasing $\mathrm{Ca}_{\mathrm{e}}$ also alters the amplitude of facilitation, defined as $\left(\mathrm{EPSC}_{2}-\mathrm{EPSC}_{1}\right) / \mathrm{EPSC}_{1}$, and the time course of facilitation. In $1 \mathrm{mM} \mathrm{Ca}_{\mathrm{e}}$, for an interstimulus interval of $20 \mathrm{~ms}$, the amplitude of facilitation is $5.5 \pm 0.4$ (Fig. $1 b$, squares). In $2.5 \mathrm{mM} \mathrm{Ca}_{\mathrm{e}}$, the amplitude of facilitation at $20 \mathrm{~ms}$ decreases to $1.6 \pm 0.1$ (Fig. $1 b$, circles). This trend is observed over a range of $\mathrm{Ca}_{\mathrm{e}}$, with the amplitude of facilitation decreasing as $\mathrm{Ca}_{\mathrm{e}}$ increases (Fig. 1c). The dependence of the amplitude of facilitation on $\mathrm{Ca}_{\mathrm{e}}$ and the initial probability of release is a property of most types of synapses, but it is not well understood. As the interstimulus interval increases, the amplitude of facilitation decays to zero. The time course of the decay of facilitation becomes slower as $\mathrm{Ca}_{\mathrm{e}}$ increases, as is most apparent when the curves are normalized to the maximum amplitude of facilitation (Fig. 1d). The time constant of decay increased from $80 \mathrm{~ms}$ in $1 \mathrm{~mm} \mathrm{Ca}$ to $210 \mathrm{~ms}$ in $2.5 \mathrm{Ca}_{\mathrm{e}}$. These properties of facilitation raise two questions. First, do MVR and saturation or glutamate pooling during the second EPSC limit the extent of facilitation and account for the decrease in facilitation 
a
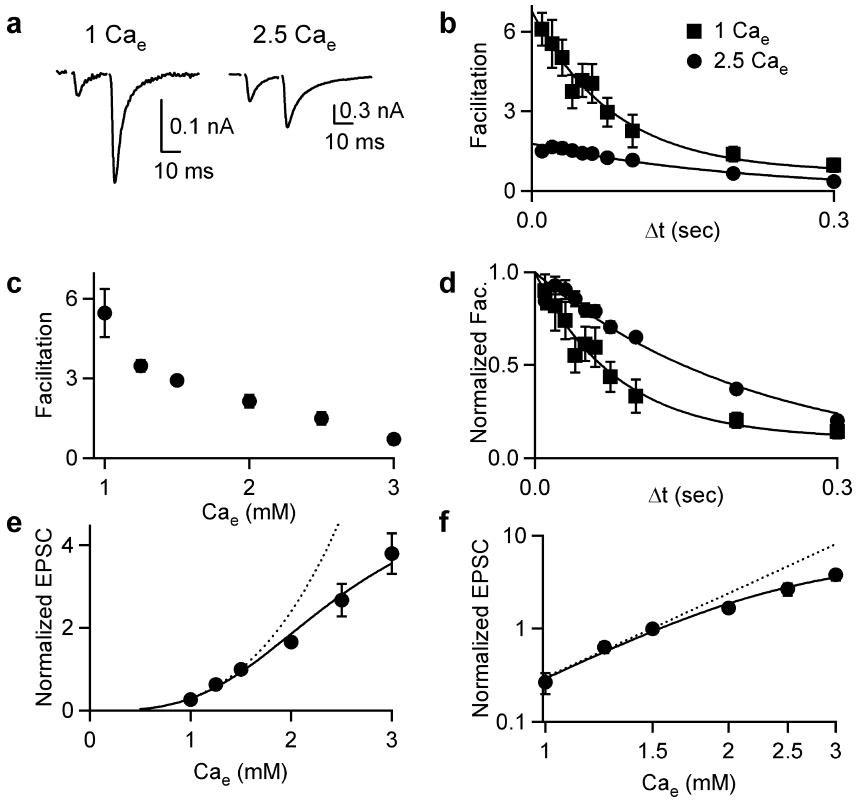

Figure 1. The effect of extracellular calcium on synaptic transmission at the parallel fiber synapse. $\boldsymbol{a}$, A representative experiment showing two EPSCs elicited $20 \mathrm{~ms}$ apart in $1 \mathrm{~mm} \mathrm{Ca}$ (left) and in $2.5 \mathrm{~mm} \mathrm{Ca}$ (right) in the same cell. Traces are the average of six trials. $\boldsymbol{b}$, The time course of facilitation, defined as (EPSC - EPSC $_{1}$ )/EPSC $C_{1}$, is shown for $2.5 \mathrm{~mm} \mathrm{Ca}_{\mathrm{e}}$ (circles) and 1 $\mathrm{mm} \mathrm{Ca}_{\mathrm{e}}$ (squares). Points are the average of seven experiments. The data are fit to the following equation: facilitation $=A e^{-\Delta t / \tau}$, with fit parameters $[A, \tau(\mathrm{ms})]$ of $[1.7,210]$ for $2.5 \mathrm{~mm} \mathrm{Ca}$, and $[6.1,86]$ for $1 \mathrm{~mm} \mathrm{Ca}$. c, The amplitude of facilitation is plotted as a function of $\mathrm{Ca}_{\mathrm{e}}$. Each point is the average of $4-11$ experiments and corresponds to the amplitude of facilitation for $\Delta t=20 \mathrm{~ms}$. $\boldsymbol{d}$, The facilitation curves from $\boldsymbol{b}$ were normalized to the extrapolated value of facilitation at $\Delta t=0 \mathrm{~ms}$ and replotted to better illustrate the $\mathrm{Ca}_{\mathrm{e}}$ dependence of the time course of facilitation. $\boldsymbol{e}, \boldsymbol{f}$, EPSC amplitude is plotted as a function of $\mathrm{Ca}_{\mathrm{e}}$. EPSC amplitudes were normalized to the EPSC amplitude in $1.5 \mathrm{Ca}_{\mathrm{e}}$. Three to five experiments were averaged for each point. The solid line in e and $f$ is a fit of the data to Equation 2, where EPSC $\mathrm{MAX}_{\mathrm{MA}}=5.4 \pm 2.6, \mathrm{Ca}_{0.5}$ $=1.4 \pm 0.3 \mathrm{~mm}$, and $n=4.8 \pm 1.0$. The dashed line represents a fit of the first three data points to Equation 1 , with $k=1.01 \pm 0.04$ and $n=4.9 \pm 0.5$. The data in $e$ are replotted as a logarithmic plot in $\boldsymbol{f}$. Error bars are SEM, and some error bars are obscured by points.

with increasing $\mathrm{Ca}_{\mathrm{e}}$ ? Second, do they contribute to the increase in the time constant of decay of facilitation that also occurs when $\mathrm{Ca}_{\mathrm{e}}$ is increased?

A final issue is the calcium dependence of synaptic transmission. As $\mathrm{Ca}_{\mathrm{e}}$ is increased, the amplitude of the EPSC also increases (Fig. 1e). A logarithmic plot shows that the relationship is approximately linear when $\mathrm{Ca}_{\mathrm{e}}$ is below $2 \mathrm{~mm}$ (Fig. $1 f$ ). This corresponds to a relationship in which

$$
\mathrm{EPSC}=k\left(\mathrm{Ca}_{\mathrm{e}}\right)^{n},
$$

where $n=3$. However, when $\mathrm{Ca}_{\mathrm{e}}$ is elevated to $3 \mathrm{~mm}$, the EPSC amplitude appears to saturate, and the data are well approximated by the function

$$
\mathrm{EPSC}=\frac{\operatorname{EPSC}_{\operatorname{MAX}}\left(\mathrm{Ca}_{\mathrm{e}}\right)^{n}}{\left(\mathrm{Ca}_{\mathrm{e}}\right)^{n}+\left(\mathrm{Ca}_{0.5}\right)^{n}},
$$

where EPSC $_{\text {MAX }}$ is the maximum EPSC that can be evoked, $n$ is a measure of the $\mathrm{Ca}_{\mathrm{e}}$ dependence, and $\mathrm{Ca}_{0.5}$ is the value of $\mathrm{Ca}_{\mathrm{e}}$ at which the EPSC is half-maximal. The saturation of EPSC amplitude with increasing $\mathrm{Ca}_{\mathrm{e}}$ has been observed at numerous synapses (Dodge and Rahamimoff, 1967; Reid et al., 1998; Schneggenburger and Neher, 2005). The observed dependence of the EPSC on $\mathrm{Ca}_{\mathrm{e}}$ raised the issue of whether MVR and AMPAR saturation or glutamate pooling contribute to the saturation of EPSC amplitude.

\section{The effects of DGG and NBQX on facilitation}

We tested whether either MVR and AMPAR saturation or glutamate pooling influence facilitation by comparing facilitation measured in control conditions with facilitation in the presence of either a fast, low-affinity AMPAR antagonist or a slow highaffinity AMPAR antagonist. DGG relieves AMPAR saturation because it rapidly dissociates from AMPARs and effectively competes with glutamate. In contrast, NBQX is a slowly dissociating antagonist that does not affect receptor saturation because glutamate cannot compete for receptors during its brief time in the synaptic cleft. NBQX at $250 \mathrm{~nm}$ and DGG at $5 \mathrm{~mm}$ reduced the amplitude of the PF EPSC to a similar extent in $3 \mathrm{mM} \mathrm{Ca}_{\mathrm{e}}[11 \pm$ $1 \%$ of control $(n=12)$ for DGG and $16 \pm 1 \%$ of control $(n=10)$ for NBQX], which allowed us to use similar stimulus intensities to study facilitation in the presence of either DGG, which should relieve AMPAR saturation, or NBQX, which should not.

Representative experiments show that DGG and NBQX have very different effects on facilitation at PF synapses. These experiments were conducted in the presence of $3 \mathrm{mM} \mathrm{Ca}_{\mathrm{e}}$, and PF synapses were activated with pairs of pulses every $15 \mathrm{~s}$. DGG

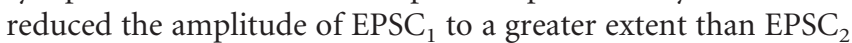
(Fig. $2 a$ ). This is shown by the reversible increase in the amplitude of facilitation as a function of time (Fig. $2 a$, bottom left). It is also apparent in the plot of the normalized EPSCs measured in control conditions and in the presence of DGG (Fig. $2 a$, right). In contrast, NBQX reduced the amplitude of both EPSCs to the same extent, and facilitation remained constant (Fig. 2b). On average, DGG significantly increased facilitation by $(99 \pm 18 \%$; $n=4 ; p<0.02$, paired Student's $t$ test), whereas NBQX did not significantly alter the extent of facilitation $(3 \pm 12 \% ; n=4 ; p>$ 0.8 ). These experiments suggest that the more prominent facilitation in the presence of DGG does not arise from series resistance errors and is consistent with either MVR and postsynaptic receptor saturation or glutamate pooling and spillover.

We also compared facilitation in DGG and in NBQX within the same synapses. In these experiments, PF EPSCs were stimulated with pairs of stimuli in the presence of $5 \mathrm{~mm}$ DGG, and then the external solution was switched to $250 \mathrm{~nm} \mathrm{NBQX}$. After allowing 20 min for the DGG to wash from the slice and for the NBQX to equilibrate, the EPSCs were again measured. The stimulus intensity was kept constant, and the same population of fibers was activated. As shown in the representative experiment in $3 \mathrm{~mm} \mathrm{Ca}_{\mathrm{e}}$, the amplitude of EPSC $_{1}$ was approximately the same in both conditions, but there was much more facilitation in the presence of DGG (Fig. 2c). In this example, the facilitation was 1.79 in DGG and 0.86 in NBQX. On average, the ratio of the amplitude of facilitation in DGG to the amplitude of facilitation in NBQX was $1.65 \pm 0.16(n=4 ; p<0.02$, paired $t$ test $)$. Although the larger facilitation in DGG compared with control conditions and NBQX is consistent with MVR and postsynaptic receptor saturation, a decrease in the initial probability of release could also cause an increase in facilitation (Zucker and Regehr, 2002). We determined whether DGG affected the presynaptic release probability by measuring STCs in Purkinje cells. This current arises from the glutamate released from the parallel fibers and provides a sensitive means of detecting changes in glutamate release. STCs were measured in the absence of chloridepermeable anions as described previously (Zerangue and Kavanaugh, 1996; Bergles et al., 1997; Auger and Attwell, 2000; Wadiche and Jahr, 2001). NBQX (25 $\mu \mathrm{M})$ was added to block 
a
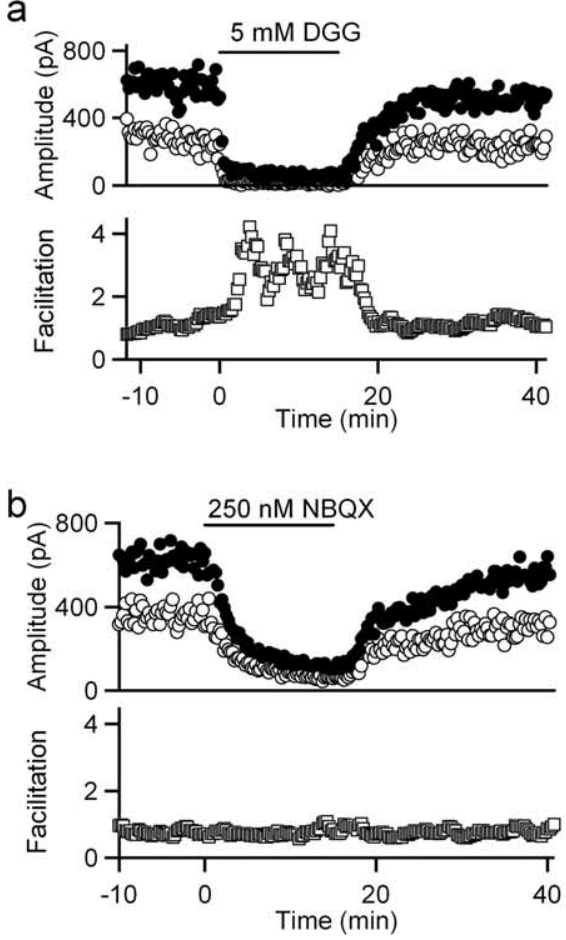

C

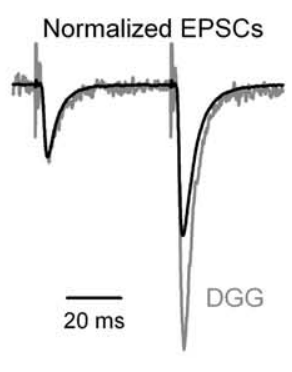

5 mM DGG

$250 \mathrm{nM}$ NBQX

Normalized
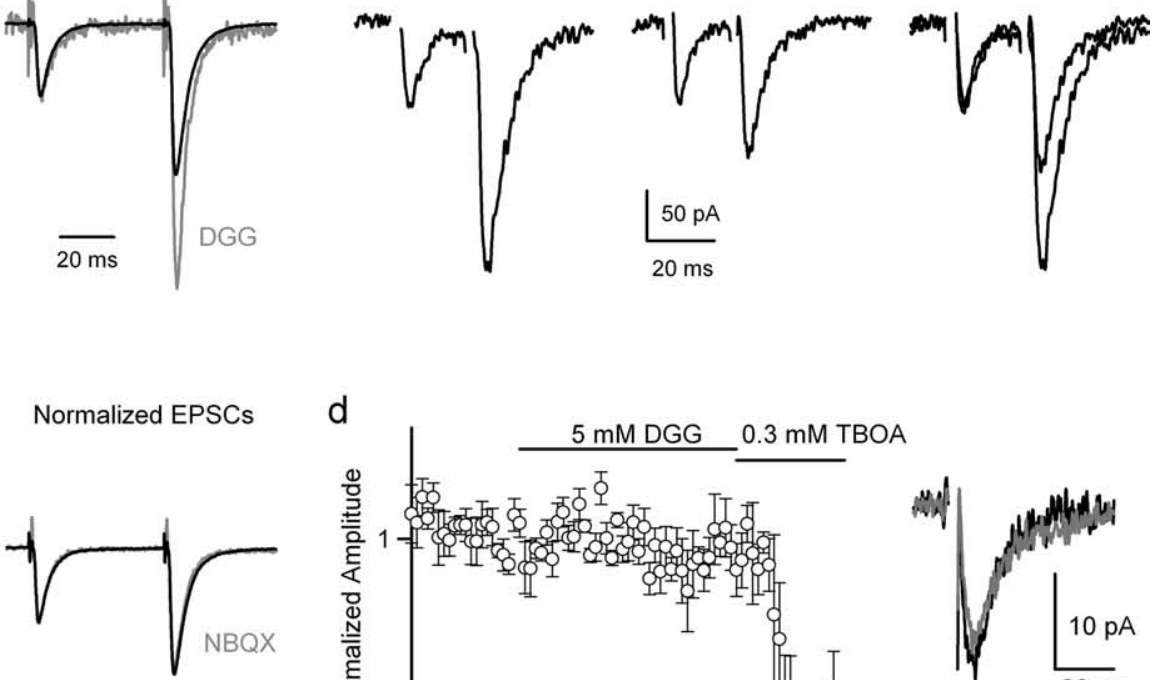

d

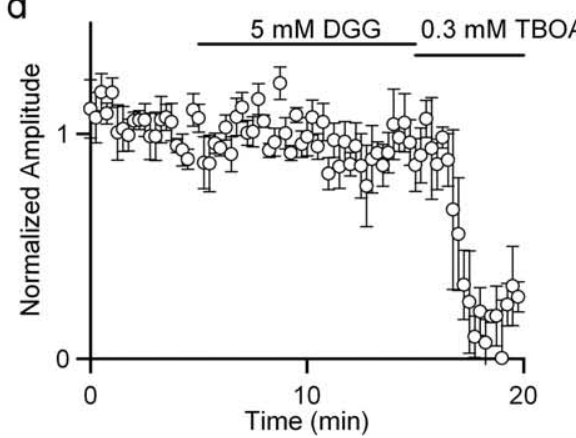

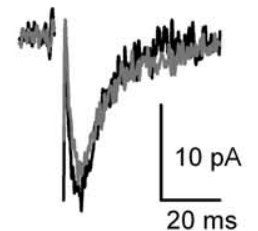

Figure 2. DGG enhances facilitation of PF synapses without altering glutamate release. PF EPSCs were evoked with pairs of stimuli ( $\Delta t=50 \mathrm{~ms}$ ) every $15 \mathrm{~s}$, and the effects of $5 \mathrm{~mm}$ DGG (a) and $250 \mathrm{~nm} \operatorname{NBQX}(\boldsymbol{b})$ on the amplitudes of EPSC (open circles, top left), EPSC (filled circles, top left), and facilitation (open squares, bottom left) are plotted as a function of time. To reduce the effect of stochastic variation, the amplitude of facilitation is calculated from the running average of 10 traces. The average EPSCs recorded in control conditions ( $\boldsymbol{a}, \boldsymbol{b}$, black, right), in the presence of DGG ( $\boldsymbol{a}$, gray, right) and in the presence of NBQX ( $\boldsymbol{b}$, gray, right) are normalized to $\mathrm{EPSC}_{1} . \boldsymbol{c}$, EPSCs were evoked with pairs of stimuli separated by $20 \mathrm{~ms}$ in the presence of $5 \mathrm{~mm} \mathrm{DGG} \mathrm{(left).} \mathrm{Then,} \mathrm{the} \mathrm{external}$ solution was changed to $250 \mathrm{~nm} \mathrm{NBQX}$, and the average response was determined after 20 min in NBQX (middle). The traces measured in NBQX and DGG are normalized to the amplitude of EPSC for the purposes of comparing the extent of facilitation (right). $\boldsymbol{d}$, Synaptic transporter currents were evoked with PF stimulation and measured with a $0 \mathrm{Cl}^{-}$internal in the presence of $25 \mu \mathrm{M} \mathrm{NBQX}$ to block AMPAR EPSCs. The effect of $5 \mathrm{~mm} \mathrm{DGG} \mathrm{was} \mathrm{assessed,} \mathrm{and} \mathrm{the} \mathrm{average} \mathrm{amplitude} \mathrm{of} \mathrm{the} \mathrm{transporter} \mathrm{currents} \mathrm{measured} \mathrm{in} \mathrm{control} \mathrm{conditions,} \mathrm{in} 5 \mathrm{~mm} \mathrm{DGG,} \mathrm{and} \mathrm{in} \mathrm{the} \mathrm{presence} \mathrm{of} \mathrm{TBOA} \mathrm{is} \mathrm{plotted}$ as a function of time $(n=6)$. Transporter currents are shown on the right, with control trace (black) and the response in $5 \mathrm{~mm}$ DGG (gray) superimposed.

EPSCs mediated by AMPARs, and a small current remained that was typically $\sim 1-2 \%$ of the initial EPSC amplitude. The STC was blocked by the broad-spectrum glutamate transport inhibitor TBOA $(300 \mu \mathrm{M})$, indicating that is was mediated by glutamate transporters in the Purkinje cell (Fig. $2 d$ ). In the presence of DGG ( $5 \mathrm{~mm})$, the STC amplitude was $94 \pm 5 \%$ of control $(n=6)$. This lack of effect of DGG on transporter currents is consistent with studies of CF, in which $2 \mathrm{~mm}$ DGG did not affect transporter currents (Wadiche and Jahr, 2001). Based on our studies of the calcium dependence of facilitation and the observed relationship between the EPSC amplitude and the extent of facilitation (Fig. 1), it would take an $\sim 25 \%$ reduction in the initial probability of release to account for the observed increase in facilitation in the presence of DGG. The finding that DGG does not alter transporter currents indicates that the effects of DGG on paired-pulse plasticity reflect the interaction of DGG with postsynaptic AMPARs.

\section{The effect of DGG on facilitation after stimulation in the granular layer}

DGG can affect the extent of facilitation when MVR occurs at an individual site or when multiple synapses are activated and glutamate spillover and pooling occur. PF to Purkinje cell synapses are similar to CF synapses in that they are well ensheathed by glia and individual release sites and their corresponding postsynaptic densities appear to be isolated (Xu-Friedman et al., 2001). This suggests that glutamate pooling is less prominent than at other synapses in which release sites and PSDs are close together and are less well isolated (Carter and Regehr, 2000; Xu-Friedman and Regehr, 2004). However, stimulation of a beam of fibers by an extracellular electrode in the molecular layer will activate many synapses in close proximity to each other, which could lead to glutamate pooling (Marcaggi et al., 2003).

We therefore tested the effects of DGG on facilitation when PF synapses were activated in a manner that minimized any potential contribution of glutamate pooling (Marcaggi et al., 2003). Granule cell axons were activated with two electrodes placed in the granular layer (Fig. 3a). Because granule cells extend their axons different distances into the molecular layer, the synapses activated in this manner will be distributed throughout the dendritic arbor of the Purkinje cell, and the contribution of glutamate pooling is minimized. In control conditions, the facilitation in $3 \mathrm{mM} \mathrm{Ca}_{\mathrm{e}}$ was $68 \pm 4 \%(n=10)$. We then examined the effects of washing in either DGG or NBQX on the magnitude of facilitation. DGG ( $5 \mathrm{~mm}$ ) reduced the amplitude of the first EPSC to $9 \pm 1 \%$ of initial values and increased facilitation from $0.67 \pm$ 0.07 to $1.47 \pm 0.08$, which represents a $126 \pm 15 \%$ increase in facilitation ( $n=5 ; p<0.001$, paired Student's $t$ test) (Fig. $3 b)$. NBQX $(250 \mu \mathrm{M})$ reduced the amplitude of the initial EPSC to $15 \pm 1 \%$ of initial values, and facilitation increased from $0.70 \pm$ 0.04 to $0.82 \pm 0.08$, which represents a $16 \pm 7 \%$ increase in facilitation $(n=5 ; p>0.05)$ (Fig. $3 c$ ). The small increase in the extent of facilitation in NBQX is likely attributable to series resistance errors, which cause a slight underestimate of the extent of facilitation in control conditions in which the EPSCs were quite large. The increase in the magnitude of facilitation in the presence of DGG for granular stimulation was similar to that observed for molecular layer stimulation. This suggests that glutamate pooling 
a

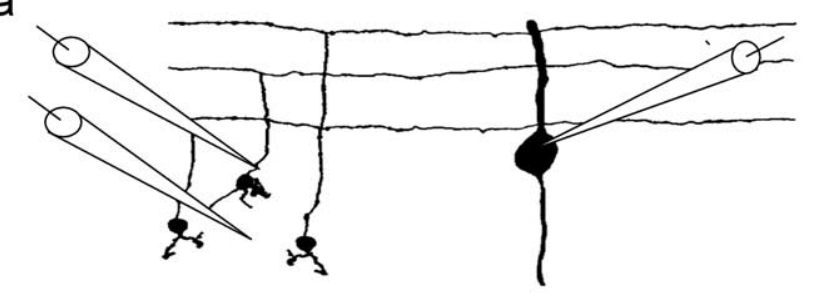

b
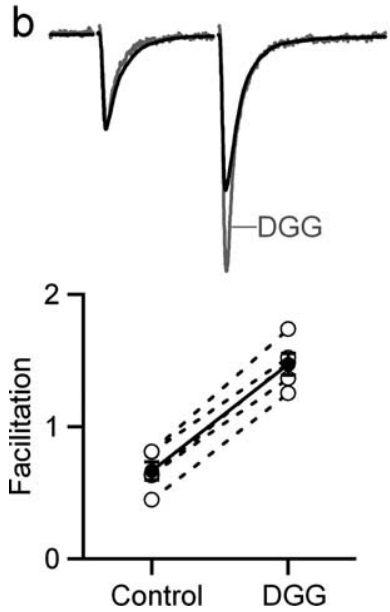
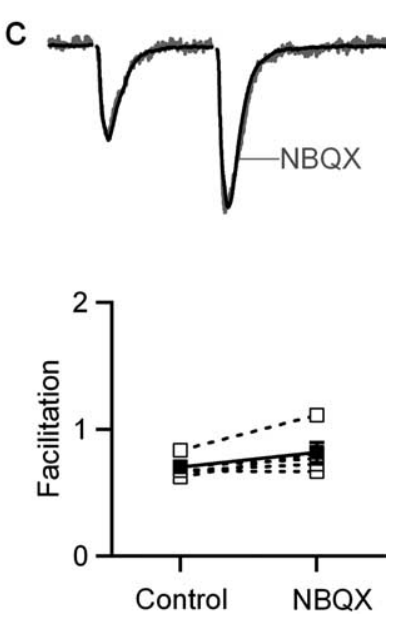

Figure 3. The effects of glutamate receptor antagonists on facilitation under conditions in which glutamate pooling is minimal. $\boldsymbol{a}$, Schematic showing the manner in which granule cells within a transverse slice were activated with electrodes placed in the granular layer, and the response was recorded with a whole-cell electrode. The stimulus electrode was located $50-100$ $\mu \mathrm{m}$ lateral from the recorded Purkinje cell to avoid activation of ascending synapses from the granule cell. Therefore, the EPSCs arise from PF synapses corresponding to the axonal regions after the bifurcation in the axon. Because the axons bifurcate at various distances into the molecular layer, the activated synapses are distributed throughout the dendritic arbor. Representative pairs of EPSCs for a wash-in experiment are shown for control conditions $(\boldsymbol{b}$, black trace, top) and in the presence of DGG (b, gray trace, top) and for control conditions (c, black trace, top) and in the presence of NBQX ( $c$, gray trace, top). Summaries of facilitation in control conditions and in the presence of an antagonist are shown for wash-in experiments in DGG $(\boldsymbol{b}$, bottom) and in NBQX (c, bottom).

is unlikely to be a factor in the effect of DGG on facilitation and that the most likely explanation is MVR and AMPAR saturation.

\section{Multivesicular release and receptor saturation limit the amplitude of facilitation}

We next determined the effect of MVR and AMPAR saturation on the time course and amplitude of facilitation by examining the effects of DGG and NBQX on the properties of facilitation over a wide range of conditions. The properties of facilitation observed in control conditions were not altered in the presence of $250 \mathrm{nM}$ NBQX (Fig. 4). This can be seen both in summary data (Fig. $4 a, c, e)$, which show that the amplitude and time course of facilitation are similar in control conditions (open triangles), and in NBQX (filled circles). It is also apparent in the representative traces showing EPSC amplitudes evoked $20 \mathrm{~ms}$ apart (Fig. $4 b, d, f$,$) . The amplitude of facilitation at 20 \mathrm{~ms}$ was not significantly different whether measured in control conditions or in the presence of NBQX in $1 \mathrm{mM} \mathrm{Ca}_{\mathrm{e}}(6.1 \pm 0.2$ in control; $5.1 \pm 0.6$ in NBQX; $p>0.1)$ or when $\mathrm{Ca}_{\mathrm{e}}$ was raised to $3 \mathrm{~mm}(1.1 \pm 0.1$ in control; $1.1 \pm 0.1$ in NBQX; $p>0.5$ ). Because NBQX allowed us to study synaptic currents that were evoked by stimulation with amplitudes similar to those used to study currents evoked in DGG, and the properties of facilitation were similar in the presence of NBQX and in the absence of blocker, much of this study

a
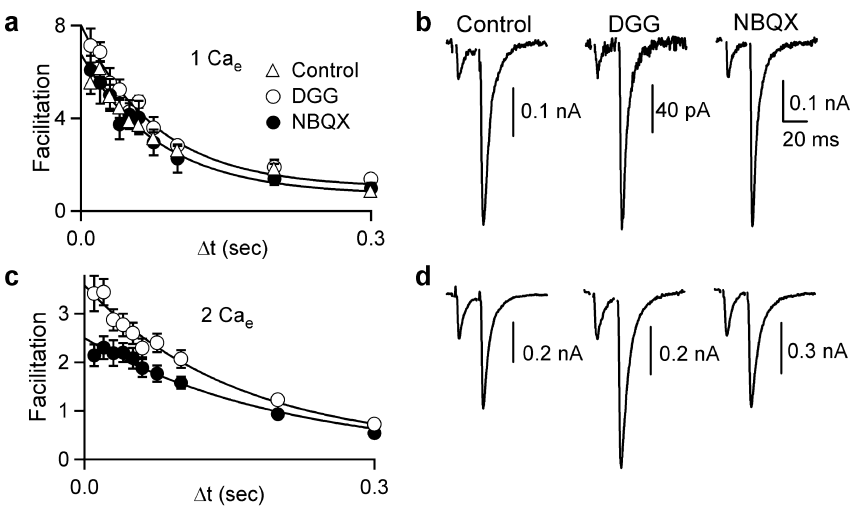

d
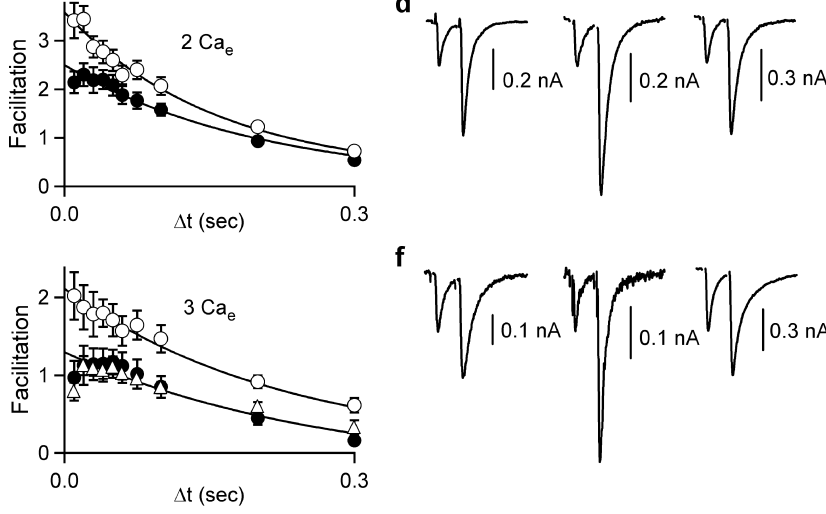

$\sqrt[n]{10.1 \mathrm{nA}} \sqrt{\mid} 0.1 \mathrm{nA} / 0.3 \mathrm{nA}$

g

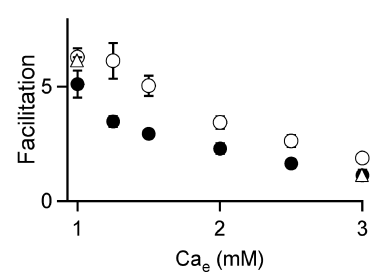

Figure 4. The effect of relieving AMPA receptor saturation on the amplitude of facilitation. The time course of facilitation is shown in the presence of $250 \mathrm{~nm}$ NBQX (filled circles), $5 \mathrm{~mm}$ DGG (open circles), and in the absence of antagonists (open triangles) for $1 \mathrm{~mm} \mathrm{Ca}_{\mathrm{e}}(\boldsymbol{a}), 2 \mathrm{~mm} \mathrm{Ca}_{\mathrm{e}}(\boldsymbol{c})$, and $3 \mathrm{~mm} \mathrm{Ca}_{\mathrm{e}}(\boldsymbol{e})$. Each point is the average of seven experiments. Data are fit to the following equation: facilitation $=A e^{-\Delta t / \tau}$, with fit parameters $[A, \tau(\mathrm{ms})]$ of $[6.7,78]$ for $1 \mathrm{~mm} \mathrm{Ca}$ plus DGG and [6.1, 86] for $1 \mathrm{~mm} \mathrm{Ca}_{\mathrm{e}}$ plus NBQX, [3.3, 160] for $2 \mathrm{~mm} \mathrm{Ca}$ plus DGG and [2.4, 200] for 2 $\mathrm{mm} \mathrm{Ca}$ plus NBQX, and $[2.7,170]$ for $3 \mathrm{~mm} \mathrm{Ca}$ plus DGG and $[1.7,210]$ for $3 \mathrm{~mm} \mathrm{Ca}_{\mathrm{e}}$ plus NBQX. Representative traces showing the EPSCs evoked by a pair of stimuli $(t=20 \mathrm{~ms})$ are shown for $1 \mathrm{~mm} \mathrm{Ca}_{\mathrm{e}}(\boldsymbol{b}), 2 \mathrm{~mm} \mathrm{Ca}(\boldsymbol{d})$, and $3 \mathrm{~mm} \mathrm{Ca}(\boldsymbol{f})$, in the absence of any antagonists (left), in the presence of DGG (middle), and in the presence of NBQX (right). Traces in $\boldsymbol{b}, \boldsymbol{d}$, and $\boldsymbol{f}$ are the average of two to three trials. $\boldsymbol{g}$, The amplitudes of facilitation $(\Delta t=20 \mathrm{~ms}$ ) in DGG (open circles), NBQX (filled circles), and in the absence of antagonists (open triangles) are plotted as a function of $\mathrm{Ca}_{\mathrm{e}}$. There was no significant difference in the extent of facilitation in $1 \mathrm{~mm} \mathrm{Ca} \mathrm{e}_{\mathrm{e}}$ in the absence of an antagonist or in the presence of either NBQX or DGG ( $p>0.1$, Student's $t$ test; $n=6 \mathrm{no}$ antagonist; $n=11 \mathrm{NBQX} ; n=11 \mathrm{DGG})$, but there were significant differences in the extent of facilitation in $1.25 \mathrm{~mm} \mathrm{Ca}_{\mathrm{e}}(p<0.01 ; n=3,3), 1.5 \mathrm{~mm} \mathrm{Ca}_{\mathrm{e}}(p<0.005 ; n=10$ NBQX, 10 DGG), $2 \mathrm{~mm} \mathrm{Ca}_{\mathrm{e}}(p<0.01 ; n=7,6), 2.5 \mathrm{~mm} \mathrm{Ca} \mathrm{e}(p<0.01 ; n=7,6)$, and $3 \mathrm{~mm} \mathrm{Ca}_{\mathrm{e}}$ $(p<0.01 ; n=10,8)$. There was no significant difference between the extent of facilitation for no antagonists versus NBQX ( $p>0.1 ; n=8$ no antagonist) in $3 \mathrm{~mm} \mathrm{Ca}_{\mathrm{e}}$.

focuses on a comparison of EPSCs evoked in the presence of 250 nM NBQX with those evoked in the presence of 5 mM DGG.

DGG did not influence facilitation in low $\mathrm{Ca}_{\mathrm{e}}$ when $p$ is low. In $1 \mathrm{mM} \mathrm{Ca}_{\mathrm{e}}$, the amplitude of facilitation was similar in the absence of any antagonist (Fig. $4 a$, open triangles), in the presence of NBQX (Fig. $4 a$, filled circles), and in the presence of 5 mM DGG (Fig. $4 a$, open circles). At $20 \mathrm{~ms}$, the amplitude of facilitation was $6.3 \pm 0.4(n=11)$ in the presence of DGG, which was not significantly different from the amplitude in NBQX $(5.1 \pm 0.6 ; n=11$; $p>0.1)$ or in the absence of antagonists $(6.1 \pm 0.2 ; n=6 ; p>$ $0.5)$. The modest effect of DGG on facilitation suggests that MVR and AMPAR saturation are not prominent at PF synapses in $1 \mathrm{mM}$ $\mathrm{Ca}_{\mathrm{e}}$. This is consistent with the low likelihood of having multiple vesicles released at a site if $p$ is low, as is the case at this synapse in $1 \mathrm{mM} \mathrm{Ca}_{\mathrm{e}}$. This also indicates that DGG does not have presynaptic effects. 

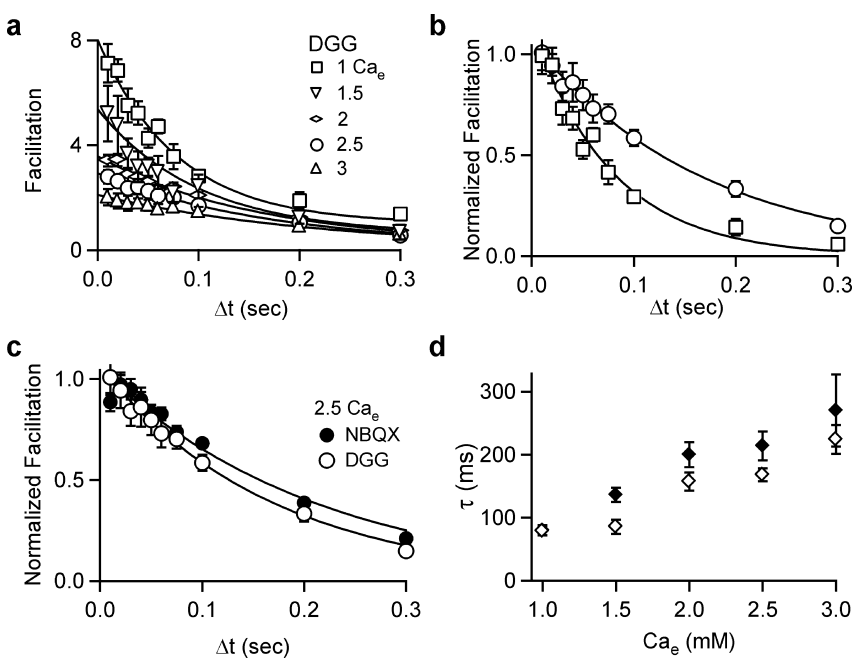

d

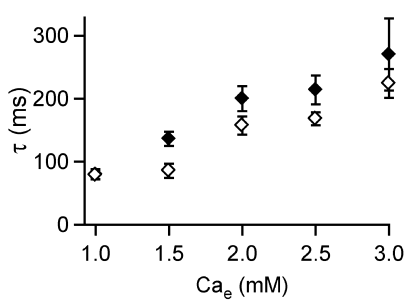

Figure 5. The effect of relieving AMPA receptor saturation on the time course of facilitation. $\boldsymbol{a}$, The facilitation recorded in $5 \mathrm{~mm} \mathrm{DGG}$ in the indicated concentrations of $\mathrm{Ca}_{\mathrm{e}}$. Curves are the average of four to eight experiments. $\boldsymbol{b}$, Normalized facilitation curves from $\boldsymbol{a}$ for 1 and $2.5 \mathrm{~mm}$ $\mathrm{Ca}_{\mathrm{e}} . c$, Normalized facilitation curves in $2.5 \mathrm{~mm} \mathrm{Ca}_{\mathrm{e}}$ recorded in $250 \mathrm{~nm} \mathrm{NBQX} \mathrm{(filled} \mathrm{circles)} \mathrm{and}$ in $5 \mathrm{~mm} \mathrm{DGG}$ (open circles). $\boldsymbol{d}$, Time constant of facilitation as a function of $\mathrm{Ca}_{\mathrm{e}}$ recorded in $250 \mathrm{~nm}$ NBQX (filled diamonds) and with AMPAR saturation relieved ( $5 \mathrm{~mm}$ DGG, open diamonds).

When $\mathrm{Ca}_{\mathrm{e}}$ was increased, the effect of relieving AMPAR saturation on facilitation was larger. In $2 \mathrm{mM} \mathrm{Ca}_{\mathrm{e}}$, the amplitude of facilitation at $20 \mathrm{~ms}$ was $3.4 \pm 0.1(n=7)$ in DGG and $2.3 \pm 0.1$ $(n=6)$ in NBQX (Fig. 4c). The amplitude of facilitation at $20 \mathrm{~ms}$ was also larger in DGG than in NBQX or in the absence of blockers when $\mathrm{Ca}_{\mathrm{e}}$ was increased to $3 \mathrm{~mm}[1.9 \pm 0.2$ in DGG; $1.1 \pm 0.1$ in NBQX; $1.1 \pm 0.1$ in control (Fig. 4e)]. The more pronounced facilitation in the presence of DGG is also apparent when representative responses to paired stimulation are compared (Fig. $4 d, f)$.

A summary of these results shows that facilitation is similar in control, NBQX, and DGG in $1 \mathrm{~mm} \mathrm{Ca}_{\mathrm{e}}$ but that, as $\mathrm{Ca}_{\mathrm{e}}$ is elevated, facilitation is more pronounced in DGG (Fig. $4 g$, open circles) than either in NBQX (Fig. $4 g$, filled circles) or in the absence of AMPAR antagonists (Fig. 4g, open triangles). This effect of DGG on facilitation suggests that MVR and AMPAR saturation occur at the PF synapse and are most pronounced when $p$ is high, namely for the second EPSC in elevated $\mathrm{Ca}_{\mathrm{e}}$. This suggests that AMPAR saturation limits the extent of facilitation in high $\mathrm{Ca}_{\mathrm{e}}$. However, in the presence of DGG, the amplitude of facilitation still decreased substantially as $\mathrm{Ca}_{\mathrm{e}}$ was increased. This indicated that AMPAR saturation only accounts for part of the decrease in facilitation that occurs as $\mathrm{Ca}_{\mathrm{e}}$ is increased.

\section{The effect of receptor saturation on the decay of facilitation}

The finding that AMPAR saturation can affect the amplitude of facilitation suggested that multivesicular release and AMPAR saturation may also be responsible for the increase in the decay time constant of facilitation observed as $\mathrm{Ca}_{\mathrm{e}}$ was increased. We therefore investigated the effect of DGG on the time constant of facilitation in different $\mathrm{Ca}_{\mathrm{e}}$. When $\mathrm{Ca}_{\mathrm{e}}$ is increased in the presence of DGG, the amplitude of facilitation decreased as in control conditions (Fig. 5a). When the curves in the presence of 1 and $2.5 \mathrm{~mm}$ $\mathrm{Ca}_{\mathrm{e}}$ are normalized to the same amplitude, it is clear that facilitation is still longer lived in $2.5 \mathrm{~mm} \mathrm{Ca}$ than $1 \mathrm{mM} \mathrm{Ca}_{\mathrm{e}}$ even when AMPAR saturation is relieved (Fig. 5b). Comparing the normalized facilitation curves obtained in $2.5 \mathrm{mM} \mathrm{Ca}_{\mathrm{e}}$ in the presence of either NBQX or DGG reveals that facilitation decays only slightly faster in the presence of DGG (Fig. $5 c$ ). Overall, as $\mathrm{Ca}_{\mathrm{e}}$ was increased, facilitation appeared to be slightly longer lived in NBQX than in DGG (Fig. 5d), and the time constants of decay were significantly different in $1.5 \mathrm{mM} \mathrm{Ca}_{\mathrm{e}}(136 \pm 11 \mathrm{~ms}$ in NBQX and $85 \pm 11 \mathrm{~ms}$ in DGG; $p<0.02$ ). However, as $\mathrm{Ca}_{\mathrm{e}}$ was increased, the change in the time constant of decay was no longer significant $\left(p>0.05\right.$ in 2 and $2.5 \mathrm{~mm} \mathrm{Ca}_{\mathrm{e}}$ and $p>0.2$ in $3 \mathrm{mM} \mathrm{Ca}_{\mathrm{e}}$ ). These results suggest that AMPAR saturation plays a small role in the prolongation of the time course of facilitation observed when $\mathrm{Ca}_{\mathrm{e}}$ is increased.

\section{The effect of receptor saturation on EPSC amplitude}

We also investigated the effect of AMPAR saturation on the amplitude of the first and second EPSCs individually. In a representative experiment, when $\mathrm{Ca}_{\mathrm{e}}$ is changed from 3 to $1.5 \mathrm{~mm}$ in the presence of NBQX, the EPSC amplitude decreases to 22\% (Fig. $6 a$ ). In the presence of $5 \mathrm{~mm}$ DGG, this change is more pronounced, as shown for a representative experiment in which the EPSC decreased to $15 \%$ (Fig. $6 b$ ). These results are summarized for a range of $\mathrm{Ca}_{\mathrm{e}}$ in Figure 6, $c$ and $d$, in which the amplitudes of the first and second EPSCs normalized to the amplitude of the first EPSC in $1.5 \mathrm{mM} \mathrm{Ca}_{\mathrm{e}}$ are plotted as a function of $\mathrm{Ca}_{\mathrm{e}}$. In the presence of NBQX, as $\mathrm{Ca}_{\mathrm{e}}$ increases, the amplitudes of both the first and second EPSCs increase (Fig. $6 c$ ). The same trend is observed in the presence of DGG, but the EPSC amplitudes are increased to a greater extent (Fig. $6 d$ ).

This result is more clearly seen when the relationships between the EPSC amplitude and $\mathrm{Ca}_{\mathrm{e}}$ are plotted on the same graph for both DGG and NBQX (Fig. $6 e-h$ ). When $\mathrm{Ca}_{\mathrm{e}}$ is low, the relationships between the first EPSC and $\mathrm{Ca}_{\mathrm{e}}$ in DGG and NBQX overlap. However, when $\mathrm{Ca}_{\mathrm{e}}$ reaches $2 \mathrm{~mm}$, the relationships begin to deviate, with the relative amplitude of the first EPSC in the presence of DGG increasing to larger values than that in NBQX (Fig. 6e,g). For the second EPSC, the relationships again overlap at low $\mathrm{Ca}_{\mathrm{e}}$. However, when $\mathrm{Ca}_{\mathrm{e}}$ reaches $1.5 \mathrm{~mm}$, the amplitude of the second EPSC in DGG continues to increase, whereas the amplitude of the second EPSC in NBQX saturates (Fig. $6 f, h$ ). These results again suggest that, when $p$ becomes sufficiently high, MVR and AMPAR saturation occur. At the parallel fiber synapse, this begins to occur for the first EPSC when $\mathrm{Ca}_{\mathrm{e}}$ is $2 \mathrm{mM}$ or higher and occurs for the second EPSC once $\mathrm{Ca}_{\mathrm{e}}$ is higher than $1.5 \mathrm{~mm}$.

To determine the calcium dependence of synaptic strength at PF synapses, it is necessary to take into account the sublinear relationship between $\mathrm{Ca}_{\mathrm{e}}$ and calcium influx $\left(\mathrm{Ca}_{\text {influx }}\right)$. At PF synapses, $\mathrm{Ca}_{\text {influx }}=\mathrm{Ca}_{\mathrm{e}} /\left(1+\mathrm{Ca}_{\mathrm{e}} / \mathrm{Ca}_{1 / 2}\right)$, where $\mathrm{Ca}_{1 / 2}=3 \mathrm{~mm}$ (Mintz et al., 1995). Using this relationship, the amplitudes of EPSC $_{1}$ and EPSC $_{2}$ were replotted as a function of $\mathrm{Ca}_{\text {influx }}$ (Fig. $6 i, j)$. In control conditions, the relationships were well approximated by the equation

$$
\mathrm{EPSC}=\frac{\operatorname{EPSC}_{\text {MAX }}\left(\mathrm{Ca}_{\text {influx }}\right)^{n}}{\left(\mathrm{Ca}_{\text {influx }}\right)^{n}+\left(\mathrm{Ca}_{0.5}\right)^{n}},
$$

where EPSC $_{\text {MAX }}$ is the maximum EPSC that can be evoked, $n$ is measure of the dependence of the EPSC on $\mathrm{Ca}_{\text {influx }}$, and $\mathrm{Ca}_{0.5}$ is the value of $\mathrm{Ca}_{\text {influx }}$ at which the EPSC is half-maximal. When $\mathrm{Ca}_{\text {influx }} \ll \mathrm{Ca}_{0.5}$, then saturation of the EPSC amplitude is minimal and the equation reduces to

$$
\mathrm{EPSC}=k\left(\mathrm{Ca}_{\text {influx }}\right)^{n},
$$

where $\left.k=\mathrm{EPSC}_{\max } / \mathrm{Ca}_{0.5}\right)^{n}$ is a constant. Equation 4 corresponds to a straight line with a slope of $n$ on a logarithmic plot and fits the relationship between $\mathrm{EPSC}_{1}$ and $\mathrm{Ca}_{\text {influx }}$ in control conditions for 


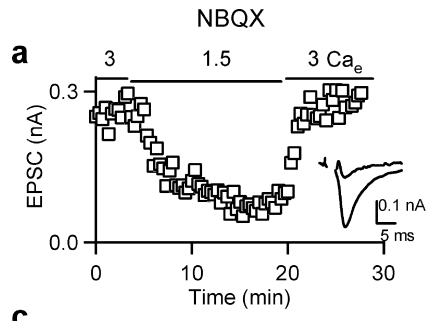

C

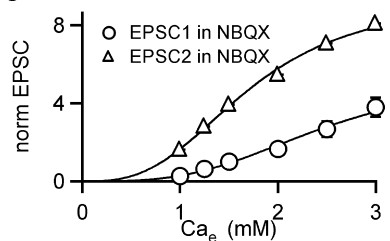

e
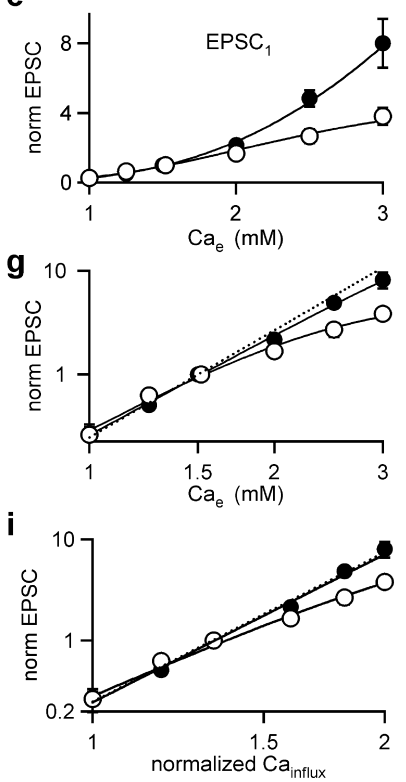

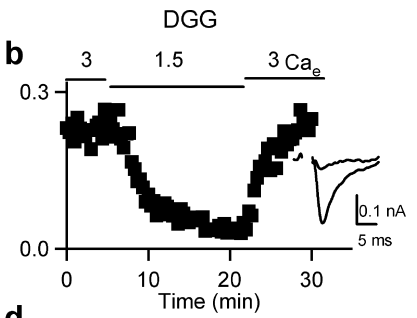

d

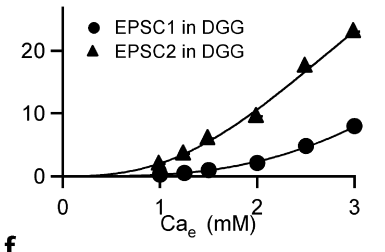

f

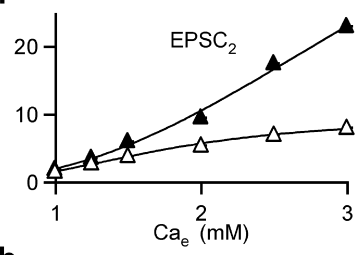

h
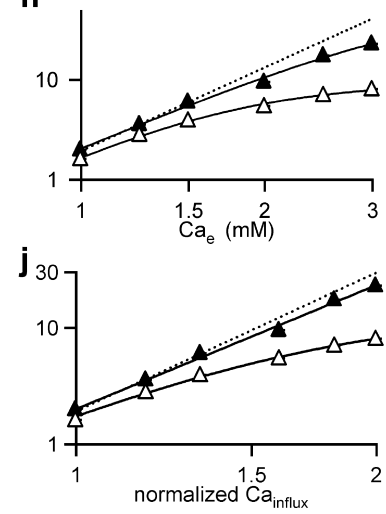

and $\mathrm{EPSC}_{2}$ were well approximated by Equation 4 with $n=4.9$ (Fig. 6i) and $n=3.8$ (Fig. 6j), respectively. This suggests that the deviation from Equation 3 in the presence of NBQX reflects MVR and AMPAR saturation. These findings also suggest that the EPSC amplitude does not provide a good measure of neurotransmitter release in control conditions and in the presence of NBQX because AMPAR saturation occurs (see Discussion).

\section{Simulating the effects of MVR and AMPAR saturation}

These experimental results suggest that MVR and AMPAR saturation have an important influence at PF synapses. We next determined whether there is a quantitative agreement between the properties of synaptic transmission in control conditions and in the presence of DGG. The goal was to determine whether MVR and AMPAR saturation account for the differences in amplitudes of EPSC $_{1}$ and EPSC $_{2}$ observed when AMPAR saturation occurs in control conditions (Fig. $6 c$ ) and when it is prevented by the inclusion of DGG (Fig. $6 d$ ). The first step was to use the fits to Equation 2 for EPSC $_{2}$ to determine the maximum current $\left(\right.$ EPSC $\left._{\mathrm{MAX}}\right)$ and then express the synaptic currents relative to EPSC $_{\text {MAX }}$ for both control conditions (Fig. 7a) and DGG (Fig. $7 b$ ). In control conditions, EPSC/EPSC MAX $_{\text {does not provide a }}$ measure of $p$ because of AMPAR saturation. When receptor saturation is relieved in the presence of DGG, the synaptic currents provide a much better estimate of neurotransmitter release, and EPSC/EPSC $_{\mathrm{MAX}}$ is approximately proportional to the probability of release of a single vesicle $\left(p_{\mathrm{v}}\right)$. This plot in DGG suggests that the initial $p_{\mathrm{v}}$ is $\sim 0.01$ in $1.5 \mathrm{mM} \mathrm{Ca}$ and that $p_{\mathrm{v}}$ increases to $\sim 0.4$ for $\mathrm{EPSC}_{2}$ in $3 \mathrm{Ca}_{\mathrm{e}}$. In contrast, in control conditions, in $3 \mathrm{Ca}_{\mathrm{e}}$ $\mathrm{EPSC}_{2}$ is over $0.8 \mathrm{EPSC}_{\max }$.

The next step was to determine whether a model based on MVR and AMPAR saturation accounts for the differences between Figure 7, $a$ and $b$. We assumed that synaptic transmission at an individual release site involves $n$ docked vesicles each with a probability of release $p_{\mathrm{v}}$. The probability of releasing $k$ vesicles is then given by the binomial distribution,

$$
p_{k}=p^{k}(1-p)^{n-k} \frac{n !}{k !(n-k) !} .
$$

EPSCS. Representative experiments showing the effect of changing $C_{\mathrm{e}}$ from 3 to $1.5 \mathrm{~mm}$ and back to $3 \mathrm{~mm}$ in the presence of $250 \mathrm{~nm} \mathrm{NBQX} \mathrm{(a)} \mathrm{and} \mathrm{in} \mathrm{the} \mathrm{presence} \mathrm{of} 5 \mathrm{~mm} \mathrm{DGG} \mathrm{(b)}$. Experiments as in $\boldsymbol{a}$ and $\boldsymbol{b}$ were used to determine the dependence of EPSC (circles) and EPSC $_{2}$ (triangles) on $\mathrm{Ca}_{\mathrm{e}}$ in NBQX (c) and in DGG (d). The lines are fits to Equation 2, where [EPSC ${ }_{\text {max }}$ $\left.\mathrm{Ca}_{0.5}, n\right]$ are $[5.4,2.4,3.2]$ for EPSC $C_{1}$ in control, $[9.5,1.7,2.9]$ for EPSC $_{2}$ in control, [61.9, 5.5, 3.2] for EPSC in DGG, and $[61.9,3.7,2.6]$ for EPSC, in DGG. The EPSCs in cand $\boldsymbol{d}$ are normalized to the amplitude of EPSC $C_{1}$ recorded in $1.5 \mathrm{~mm} \mathrm{Ca}$. The amplitudes of $\operatorname{EPSC}_{1}(\boldsymbol{e}, \boldsymbol{g})$ and $\operatorname{EPSC}_{2}(\boldsymbol{f}, \boldsymbol{h})$ recorded in NBQX (open symbols) and in DGG (filled symbols) and corresponding fits are plotted

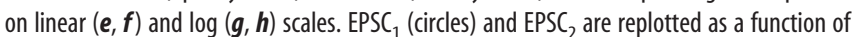
$\mathrm{Ca}_{\text {influx }}$ in $\boldsymbol{i}$ and $\boldsymbol{j}$, in which $\mathrm{Ca}_{\text {influx }}$ is determined from $\mathrm{Ca}_{\mathrm{e}}$ using the relationship determined

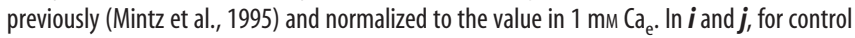
conditions, the lines are fits to Equation 3, where [EPSC $\left.\mathrm{Eax}_{\operatorname{mo}} \mathrm{Ca}_{0.5,}, n\right]$ are $[13,2.5,4.2]$ for $\operatorname{EPSC}_{1}$ and $[13,1.7,3.4]$ for $\operatorname{EPSC}_{2}$, and, in the presence of $\mathrm{DGG}$, fits are to Equation 4 , where $[k, n]$ are $[0.24,4.9]$ for EPSC$_{1}$ and $[2.0,3.5]$ for EPSC $_{2}$.

low values of $\mathrm{Ca}_{\text {influx }}$ (Fig. $6 i$, dashed line) $(n=4.9)$. However, for higher values of $\mathrm{Ca}_{\text {influx }}, \mathrm{EPSC}_{1}$ measured in control conditions deviates from this relationship and is best described by Equation 3. In control conditions, EPSC $_{2}$ also deviates from Equation 4 (Fig. $6 j$, dashed line) $(n=3.9)$ but is well approximated by Equation 3. Thus, in control conditions, the relationships between $\mathrm{EPSC}_{1}$ and $\mathrm{EPSC}_{2}$ and $\mathrm{Ca}_{\text {influx }}$ are qualitatively similar to those relating $\mathrm{EPSC}_{2}$ and $\mathrm{EPSC}_{1}$ to $\mathrm{Ca}_{\mathrm{e}}$, but there is a steeper dependence on $\mathrm{Ca}_{\text {influx }}$ than on $\mathrm{Ca}_{\mathrm{e}}$ ( $n$ is 4.2 vs 3.2 for $\mathrm{EPSC}_{1}$ and 3.4 vs 2.9 for $\mathrm{EPSC}_{2}$ ).

When AMPAR saturation was removed with DGG, EPSC ${ }_{1}$

Previous studies have shown that there are an average of seven morphologically docked vesicles (i.e., $n=7$ ) at each release site at PF synapses (Xu-Friedman et al., 2001), so that as $p_{\mathrm{v}}$ varies between 0 and 1 , the probability of having $k$ vesicles released at an individual site is shown in Figure $7 c$. If the amplitude of the response produced by the fusion of $k$ vesicles at an individual site is given by $I_{k}$, then the size of the EPSC is given by

$$
\mathrm{EPSC}=\sum_{k=1}^{n} p_{k} I_{k} .
$$

Our experimental findings indicate that a single vesicle leads to a high extent of occupancy and a sublinear relationship between the synaptic current measured and the number of vesicles released at a single release site. The extent of the occupancy depends on the properties of the AMPARs and the glutamate signal. $\mathrm{Nu}-$ merous models have been proposed to account for the activation of AMPA receptors (Raman and Trussell, 1992; Hausser and Roth, 1997; Rosenmund et al., 1998; Benke et al., 2001; Robert and Howe, 2003; Ventriglia and Di Maio, 2003). Studies of AMPARs from Purkinje cells have given rise to a model that provides a good description of the properties of AMPARs at PF synapses (Hausser and Roth, 1997), and we therefore used this 
a
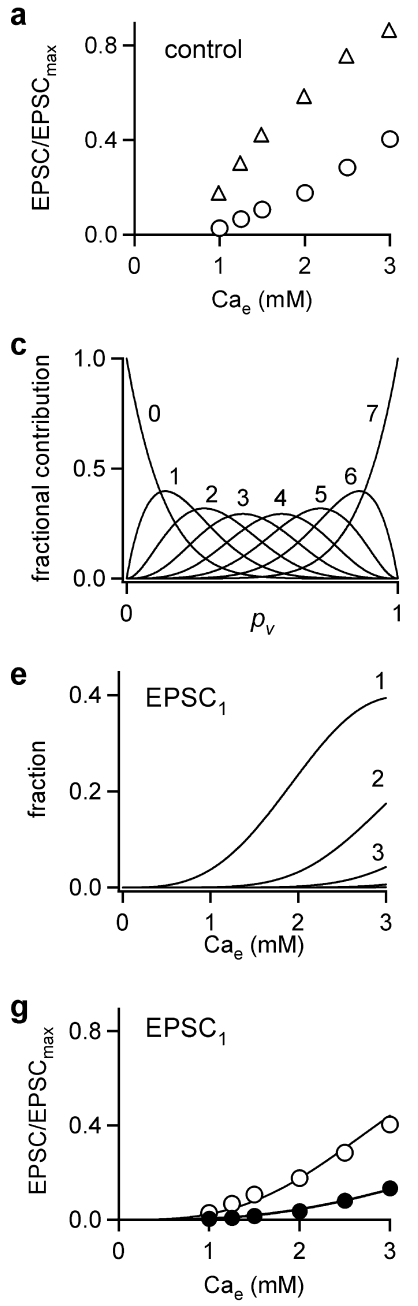
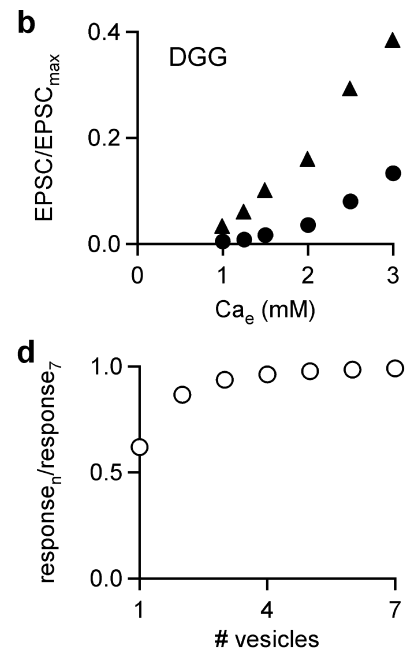

f

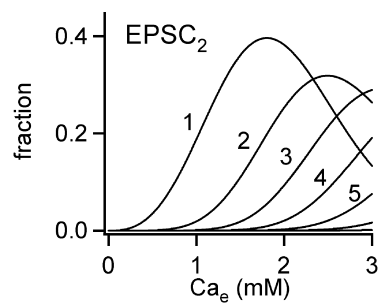

h

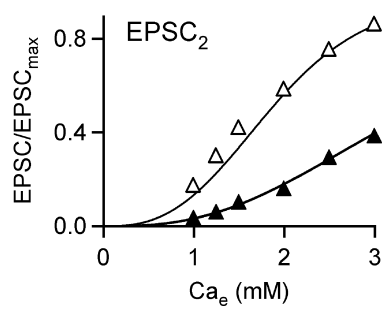

Figure 7. Modeling the $\mathrm{C}_{\mathrm{e}}$ dependence of EPSC amplitude in DGG and control based on MVR and AMPAR saturation. The model is based on seven vesicles per site that each have a probability $p_{v}$ of fusing, and the number of vesicles fusing is determined by the binomial distribution (Eq. 5). The EPSC amplitudes as a function of $\mathrm{Ca}_{\mathrm{e}}$ from Figure 6 were renormalized and replotted for experiments performed in control conditions $(\boldsymbol{a})$ and experiments performed in the presence of DGG $(\boldsymbol{b})$. The renormalizations are based on determining EPSC $_{\text {MAX }}$ by fitting the data to Equation 5.c, Fraction of events in which 0,1 . . .7 vesicles are released at site with seven docked vesicles each with $p_{v}$ calculated using Equation 5 . $\boldsymbol{d}$, Fractional response evoked by the simultaneous fusion of one to seven vesicles at a single release (see Results). Using EPSC/EPSC MAX $_{\text {as }}$ a measure of $p_{v}$ and the fits from $\boldsymbol{a}$ allowed us to calculate the fraction of sites at which $1,2, \ldots$ vesicles fused as a function of $\mathrm{Ca}_{\mathrm{e}}$ for a single pulse for $\operatorname{EPSC}(\boldsymbol{e})$ and for $\operatorname{EPSC}_{2}(\boldsymbol{f})$. These curves that describe the extent of MVR $(\boldsymbol{e}, \boldsymbol{f})$ combined with AMPAR saturation as in $\boldsymbol{d}$ were used to calculate the $\mathrm{Ca}_{\mathrm{e}}$ dependence of EPSC $\boldsymbol{C}_{1}(\boldsymbol{g})$ and EPSC $_{2}$ in control conditions $(\boldsymbol{h})$. These lines were compared with the $\mathrm{Ca}_{\mathrm{e}}$ dependence of $\mathrm{EPSC}_{1}$ (open circles) and $\mathrm{EPSC}_{2}$ (open triangles), measured in control conditions.

model to simulate responses to the release of various numbers of vesicles at PF synapses. The responses of AMPARs to the fusion of one to seven vesicles were simulated according to this model. All parameters of AMPARs used in these simulations were identical to those of Hausser and Roth (1997). The glutamate transients used in the simulations were similar to those used previously (Wadiche and Jahr, 2001): they had rise and decay times of 25 and $55 \mu \mathrm{s}$, and release of a single vesicle resulted in a peak glutamate concentration of $3.5 \mathrm{~mm}$. The amplitudes of glutamate transients scaled linearly with the number of vesicles that were synchronously released, with a maximum of $24.5 \mathrm{~mm}$ for seven vesicles. According to these simulations, the peak numbers of glutamate receptor channels open in response to one and seven vesicles are

45 and 73\%, respectively. The peaks of simulated responses were normalized to the response for seven vesicles (Fig. 7d). According to this model, the relationship between the synaptic current measured and the number of vesicles that fuse at an individual site is given by Figure $7 d$.

The next step was to determine whether these descriptions of MVR and AMPAR saturation account for the differences between the synaptic currents measured in DGG and those measured in control conditions. We first determined the fraction of vesicles released at individual sites as predicted by Equation 5, using the fits to EPSC/EPSC $\mathrm{MAX}$ in DGG as a measure of $p_{\mathrm{v}}$. The calculated $\mathrm{Ca}_{\mathrm{e}}$ dependence of the number of vesicles released at single sites reveals that MVR is exceedingly rare for $\mathrm{EPSC}_{1}$ when $\mathrm{Ca}_{\mathrm{e}}$ is $<2 \mathrm{~mm}$ (Fig. 7e). MVR is much more prominent for $\mathrm{EPSC}_{2}$, to the point that, in $3 \mathrm{Ca}_{\mathrm{e}}$, there are essentially no failures; occasionally, a site will release only a single vesicle, but at most sites, MVR occurs (Fig. 7f). We then determined the predicted $\mathrm{Ca}_{e}$ dependence of the EPSC amplitude based on the predicted number of released vesicles (Fig. 7e,f) and the fractional response to a given number of released vesicles (Fig. $7 d$ ). The resulting curves for $\mathrm{EPSC}_{1}$ (Fig. $7 g$ ) and $\mathrm{EPSC}_{2}$ (Fig. $7 \mathrm{~h}$ ) provided a remarkably good fit to the data in control conditions. This indicates that MVR and AMPAR saturation can account for the differences in the $\mathrm{Ca}_{\mathrm{e}}$ dependence of EPSC amplitude observed in control conditions and in the presence of DGG.

\section{MVR and AMPAR saturation under physiological conditions} Thus far, we have addressed the general issue of MVR and AMPAR saturation at a low $p$ synapse by examining the PF synapse at $24^{\circ} \mathrm{C}$. These findings indicate that MVR and AMPAR saturation occur even at synapses with a low probability of release and suggest that this is a common feature of synapses. The question remains as to the extent and the role of MVR and AMPAR saturation under physiological conditions. We addressed this issue by modifying our experimental conditions in several ways. Experiments were performed at near-physiological temperatures $\left(34^{\circ} \mathrm{C}\right)$ in the presence of $1.5 \mathrm{mM} \mathrm{Ca}_{\mathrm{e}}$ and $1 \mathrm{mM} \mathrm{MgCl}$, which approximates $\mathrm{Ca}_{\mathrm{e}}$ present in vivo. Spillover and glutamate pooling are less likely to occur at these near-physiological temperatures than at room temperature. PF synapses were stimulated with a brief burst of stimuli at $50 \mathrm{~Hz}$ to mimic the type of burst exhibited by granule cells in vivo (Chadderton et al., 2004).

We found that, under these conditions, DGG and NBQX still had different effects on PF EPSCs. In these experiments, the same PF synapses were activated first in the presence DGG $(2 \mathrm{mM})$ and then in the presence of NBQX $(250 \mathrm{nM})$. In the presence of NBQX, facilitation was pronounced and the amplitude of the fourth EPSC was approximately five times as large as the initial EPSC (Fig. $8 a$, black trace). This is consistent with the low initial probability of release under these conditions at this synapse. Facilitation was even more prominent in the presence of DGG (Fig. $8 a$, gray trace). The observation that the differences between the amplitudes of the EPSCs in NBQX and DGG are less pronounced for $\mathrm{EPSC}_{4}$ than for $\mathrm{EPSC}_{3}$ or $\mathrm{EPSC}_{2}$ should be interpreted cautiously. The large facilitation that develops during the train makes the measurement of late EPSCs progressively more susceptible to series resistance errors. Because the initial amplitude was larger and the extent of facilitation was greater in DGG, the difference in the amplitude of $\mathrm{EPSC}_{4}$ for DGG and NBQX may be an underestimate. A summary of $\mathrm{EPSC}_{n} / \mathrm{EPSC}_{1}$ observed in DGG and NBQX ( $n=5$ cells) showed consistent differences in facilitation during stimulus trains (Fig. 8b). This indicates that, under phys- 
a

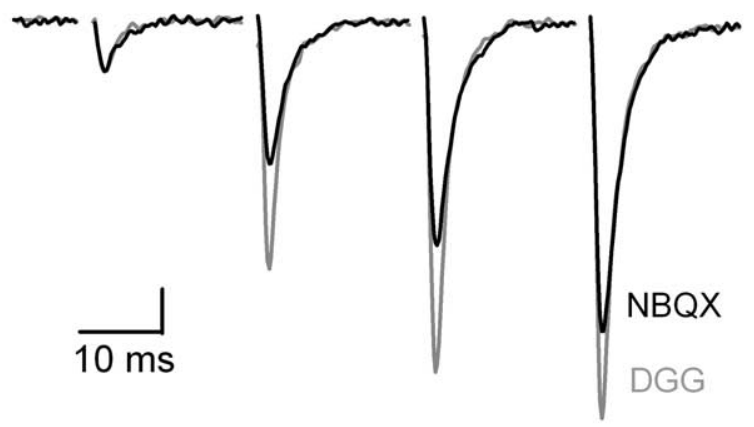

b

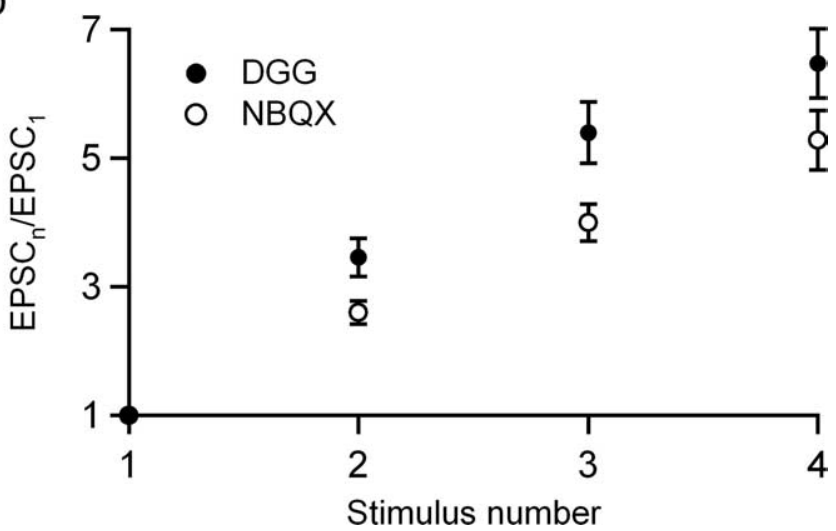

Figure 8. Multivesicular release and AMPAR saturation occur under near physiological conditions and influence use-dependent plasticity at $P F$ synapses. $\boldsymbol{a}$, A representative experiment in which PF synapses were activated at $50 \mathrm{~Hz}$ in $1.5 \mathrm{~mm} \mathrm{Ca}$ at $34^{\circ} \mathrm{C}$ in the presence of $250 \mathrm{~nm}$ NBQX (black trace) and in the presence of $2 \mathrm{~mm}$ DGG (gray trace). The peak of the first EPSC in DGG is normalized to the peak of the first EPSC in NBQX. The vertical scale bar corresponds to 60 $\mathrm{pA}$ in the presence of NBQX and $150 \mathrm{pA}$ in the presence of DGG. Traces are the average of four trials. $\boldsymbol{b}$, Summary of the peak EPSC amplitudes in 2 mM DGG (filled circles) and in NBQX (open circles) for five such experiments in which the amplitudes were normalized to EPSC ${ }_{1}$. A comparison of the responses in NBQX and DGG revealed that there were significant differences for $\mathrm{ESSC}_{2}$ $\left(p<0.05\right.$, paired Student's $t$ test), $\operatorname{EPSC}_{3}(p<0.05)$, and $\operatorname{EPSC}_{4}(p<0.03)$.

iological conditions, synaptic strength is limited by AMPAR saturation and MVR.

\section{Discussion}

We found that MVR and AMPAR saturation influence synaptic transmission at the PF to Purkinje cell synapse. These findings indicate that MVR can be prominent at synapses with a low initial release probability. Similarly, AMPAR saturation also appears to be more widespread than was initially appreciated. Together, MVR and AMPAR saturation combine to influence the calcium dependence of EPSC amplitude and limit the extent of facilitation at the PF synapse.

\section{MVR is a general feature that occurs at high and low $p$ synapses}

Previous studies have established that MVR can occur at several high $p$ synapses (Auger et al., 1998; Wadiche and Jahr, 2001), but at low $p$ synapses, the occurrence of MVR has been controversial (Stevens and Wang, 1995; Oertner et al., 2002). Previous studies of this issue examined responses mediated by individual release sites, discriminated between successes and failures, and then determined the potency (the average of the successes). Changes in $p$ are accompanied by a change in potency only at synapses in which MVR occurs. At excitatory synapses in the hippocampus, studies differ with respect to whether potency changes occurred when $p$ was altered. Electrical measurements of synaptic responses evoked by minimal stimulation found that the potency of the AMPA component remained constant even when $p$ was altered (Stevens and Wang, 1995). This study was interpreted as being consistent with release of at most a single vesicle at an individual site (i.e., no MVR). In contrast, optical measurements from individual spines indicated that changes in $p$ were accompanied by a change in the potency of the NMDA component, which supports the occurrence of MVR. Thus, one study suggests that MVR occurs at hippocampal synapses and the other suggests that it does not.

Here we find that MVR occurs at the PF synapse, which is a synapse with a low initial $p$. As at all synapses, $p$ depends on calcium entry and is regulated by use-dependent processes. In the presence of DGG with AMPAR saturation relieved the initial EPSC in $1.5 \mathrm{mM} \mathrm{Ca}_{\mathrm{e}}$ is $\sim 4 \%$ as large as the second EPSC in $3 \mathrm{~mm}$ $\mathrm{Ca}_{\mathrm{e}}$ and is $\sim 2 \%$ of the maximal EPSC estimated from fits (Fig. 6). This suggests that the initial probability of a vesicle fusing at a site $\left(p_{\mathrm{v}}\right)$ is $\sim 0.02$ in $1.5 \mathrm{mM} \mathrm{Ca}_{\mathrm{e}}$. Based on $n$ vesicles per site for each $p_{v}$, the probability of at least one vesicle being released at a site $\left(p_{\mathrm{s}}\right)$ corresponds to $p_{\mathrm{s}}=1-\left(1-p_{\mathrm{v}}\right)^{n}$, which corresponds to an initial $p_{\mathrm{s}}$ of 0.13 in $1.5 \mathrm{mM} \mathrm{Ca}_{\mathrm{e}}$. Thus, the $\mathrm{Ca}_{\mathrm{e}}$ dependence of the amplitudes of two closely spaced EPSCs indicates that the initial $p_{\mathrm{v}}$ and $p_{\mathrm{s}}$ at the PF synapse are generally quite low. Despite this low initial $p_{\mathrm{v}}$, MVR can occur at this synapse, but it is most pronounced when facilitation increases $p_{\mathrm{v}}$. The success of the model presented in Figure 7 indicates that MVR and AMPAR saturation provide a good approximation of the properties of synaptic transmission at PF synapses. This model was based on the experimentally determined number of docked vesicles at these synapses (Xu-Friedman et al., 2001), the properties of AMPAR synapses that have been described for synapses onto Purkinje cells (Hausser and Roth, 1997), and the assumption that all of the vesicles at a release site function independently and have the same probability of release. According to this model, for EPSC $_{1}$, MVR occurs at 1 and $22 \%$ of the sites in 1.5 and $3 \mathrm{mM} \mathrm{Ca}_{\mathrm{e}}$, respectively, whereas for $\mathrm{EPSC}_{2}$, MVR occurs at 13 and $83 \%$ of the sites in 1.5 and $3 \mathrm{mM} \mathrm{Ca}_{\mathrm{e}}$, respectively (Fig. $7 e, f$ ). Thus, MVR becomes prominent at this synapse for the second of two closely spaced stimuli.

\section{The use of low-affinity antagonists to study MVR}

The low-affinity antagonist approach we used here differs from measurements of potency that have been used to study MVR at other synapses. First, potency measurements are most effective at nonsaturating synapses, whereas low-affinity antagonists are most effective at saturating synapses. Potency measurements are insensitive to MVR if a single vesicle completely saturates the postsynaptic receptors because responses arising from multiple vesicles are difficult to distinguish from responses mediated by single vesicles. Thus, the lack of a potency change cannot be used to rule out MVR unless it has been established that postsynaptic receptor saturation does not occur. In contrast, the low-affinity antagonist approach is most sensitive to MVR if AMPAR saturation occurs. Second, the potency method involves the study of individual release sites, whereas the low-affinity antagonist approach is used to study the average responses of many different synapses. It has been proposed that different selection criteria for individual synapses could contribute to the differences in the results at hippocampal synapses. The low-affinity antagonist approach used here measured the population response of all acti- 
vated synapses and is therefore not prone to selection bias. Moreover, this approach does not rely on activation of individual release sites and can be used even when successes are difficult to distinguish from failures. Thus, in some circumstances, particularly when postsynaptic receptor saturation is prominent, lowaffinity receptor antagonists provide a particularly sensitive means of studying MVR. It must be noted, however, that the use of low-affinity antagonists to study populations of synapses does not provide information about differential effects on synapses with diverse properties. This is relevant to the study of granule cell synapses onto Purkinje cells, which can show considerable diversity (Isope and Barbour, 2002).

Consequences of MVR and AMPAR saturation at PF synapses The occurrence of both AMPAR saturation and MVR has numerous effects on the properties of the PF synapse. First, MVR and AMPAR saturation reduce the extent of facilitation during highfrequency bursts. Second, the time course of the EPSC is slowed. This slowing of the EPSC is similar to that described at the CF synapse, in which AMPAR saturation and MVR are prominent (Wadiche and Jahr, 2001). Third, MVR and AMPAR saturation alter the $\mathrm{Ca}_{\mathrm{e}}$ dependence of synaptic transmission. Synaptic strength of $\mathrm{EPSC}_{2}$ is half-maximal when $\mathrm{Ca}_{\mathrm{e}}$ is 1.7 and $3.4 \mathrm{~mm}$ in control conditions and in DGG, respectively. However, our findings indicate that MVR and AMPAR saturation are not responsible for the $\mathrm{Ca}_{\mathrm{e}}$ dependence of the time course of facilitation.

The consequences of MVR and receptor saturation are very different depending on the initial $p$ of the synapse. At the CF synapse that has a particularly high initial $p$, MVR is most prominent for synaptic responses evoked after a long quiescent period (Wadiche and Jahr, 2001; Foster et al., 2002; Harrison and Jahr, 2003). During sustained activity, depletion of release-ready vesicles occurs and MVR becomes less prominent. As a result, the initial synaptic response is most strongly attenuated by postsynaptic receptor saturation. This reduces the extent of depression, in effect making a more constant and reliable synapse. In contrast, at the PF synapse, MVR is not prominent for the initial EPSC when $p$ is low. Instead, MVR becomes prominent during high-frequency stimulation as $p$ is increased by facilitation.

\section{References}

Abenavoli A, Forti L, Bossi M, Bergamaschi A, Villa A, Malgaroli A (2002) Multimodal quantal release at individual hippocampal synapses: evidence for no lateral inhibition. J Neurosci 22:6336-6346.

Atluri PP, Regehr WG (1998) Delayed release of neurotransmitter from cerebellar granule cells. J Neurosci 18:8214-8227.

Atwood HL, Karunanithi S (2002) Diversification of synaptic strength: presynaptic elements. Nat Rev Neurosci 3:497-516.

Auger C, Attwell D (2000) Fast removal of synaptic glutamate by postsynaptic transporters. Neuron 28:547-558.

Auger C, Kondo S, Marty A (1998) Multivesicular release at single functional synaptic sites in cerebellar stellate and basket cells. J Neurosci 18:4532-4547.

Benke TA, Luthi A, Palmer MJ, Wikstrom MA, Anderson WW, Isaac JT, Collingridge GL (2001) Mathematical modelling of non-stationary fluctuation analysis for studying channel properties of synaptic AMPA receptors. J Physiol (Lond) 537:407-420.

Bergles DE, Dzubay JA, Jahr CE (1997) Glutamate transporter currents in bergmann glial cells follow the time course of extrasynaptic glutamate. Proc Natl Acad Sci USA 94:14821-14825.

Biro AA, Holderith NB, Nusser Z (2005) Quantal size is independent of the release probability at hippocampal excitatory synapses. J Neurosci 25:223-232.

Carter AG, Regehr WG (2000) Prolonged synaptic currents and glutamate spillover at the parallel fiber to stellate cell synapse. J Neurosci 20:4423-4434.
Chadderton P, Margrie TW, Hausser M (2004) Integration of quanta in cerebellar granule cells during sensory processing. Nature 428:856-860.

Chen G, Harata NC, Tsien RW (2004) Paired-pulse depression of unitary quantal amplitude at single hippocampal synapses. Proc Natl Acad Sci USA 101:1063-1068.

Clements JD, Lester RA, Tong G, Jahr CE, Westbrook GL (1992) The time course of glutamate in the synaptic cleft. Science 258:1498-1501.

Coesmans M, Weber JT, De Zeeuw CI, Hansel C (2004) Bidirectional parallel fiber plasticity in the cerebellum under climbing fiber control. Neuron 44:691-700.

Conti R, Lisman J (2003) The high variance of AMPA receptor- and NMDA receptor-mediated responses at single hippocampal synapses: evidence for multiquantal release. Proc Natl Acad Sci USA 100:4885-4890.

Dittman JS, Kreitzer AC, Regehr WG (2000) Interplay between facilitation, depression, and residual calcium at three presynaptic terminals. J Neurosci 20:1374-1385.

Dobrunz LE, Huang EP, Stevens CF (1997) Very short-term plasticity in hippocampal synapses. Proc Natl Acad Sci USA 94:14843-14847.

Dodge FA, Rahamimoff R (1967) Co-operative action of calcium ions in transmitter release at the neuromuscular junction. J Physiol (Lond) 193:419-432.

Foster KA, Regehr WG (2004) Variance-mean analysis in the presence of a rapid antagonist indicates vesicle depletion underlies depression at the climbing fiber synapse. Neuron 43:119-131.

Foster KA, Kreitzer AC, Regehr WG (2002) Interaction of postsynaptic receptor saturation with presynaptic mechanisms produces a reliable synapse. Neuron 36:1115-1126.

Glowatzki E, Fuchs PA (2002) Transmitter release at the hair cell ribbon synapse. Nat Neurosci 5:147-154.

Harrison J, Jahr CE (2003) Receptor occupancy limits synaptic depression at climbing fiber synapses. J Neurosci 23:377-383.

Hausser M, Roth A (1997) Dendritic and somatic glutamate receptor channels in rat cerebellar Purkinje cells. J Physiol (Lond) 501:77-95.

Herrington J, Bookman RJ (1995) Pulse control V4.5: IGOR XOPs for patch clamp data acquisition. Miami: University of Miami.

Isope P, Barbour B (2002) Properties of unitary granule cell $\rightarrow$ Purkinje cell synapses in adult rat cerebellar slices. J Neurosci 22:9668-9678.

Kirischuk S, Veselovsky N, Grantyn R (1999) Relationship between presynaptic calcium transients and postsynaptic currents at single gammaaminobutyric acid (GABA)ergic boutons. Proc Natl Acad Sci USA 96:7520-7525.

Konnerth A, Llano I, Armstrong CM (1990) Synaptic currents in cerebellar Purkinje cells. Proc Natl Acad Sci USA 87:2662-2665.

Korn H, Mallet A, Triller A, Faber DS (1982) Transmission at a central inhibitory synapse. II. Quantal description of release, with a physical correlate for binomial n. J Neurophysiol 48:679-707.

Korn H, Faber DS, Burnod Y, Triller A (1984) Regulation of efficacy at central synapses. J Neurosci 4:125-130.

Liu G, Choi S, Tsien RW (1999) Variability of neurotransmitter concentration and nonsaturation of postsynaptic AMPA receptors at synapses in hippocampal cultures and slices. Neuron 22:395-409.

Marcaggi P, Billups D, Attwell D (2003) The role of glial glutamate transporters in maintaining the independent operation of juvenile mouse cerebellar parallel fibre synapses. J Physiol (Lond) 552:89-107.

Mintz IM, Sabatini BL, Regehr WG (1995) Calcium control of transmitter release at a cerebellar synapse. Neuron 15:675-688.

Murphy GJ, Glickfeld LL, Balsen Z, Isaacson JS (2004) Sensory neuron signaling to the brain: properties of transmitter release from olfactory nerve terminals. J Neurosci 24:3023-3030.

Oertner TG, Sabatini BL, Nimchinsky EA, Svoboda K (2002) Facilitation at single synapses probed with optical quantal analysis. Nat Neurosci 5:657-664.

Perkel DJ, Hestrin S, Sah P, Nicoll RA (1990) Excitatory synaptic currents in Purkinje cells. Proc Biol Sci 241:116-121.

Raman IM, Trussell LO (1992) The kinetics of the response to glutamate and kainate in neurons of the avian cochlear nucleus. Neuron 9:173-186.

Regehr WG, Mintz IM (1994) Participation of multiple calcium channel types in transmission at single climbing fiber to Purkinje cell synapses. Neuron 12:605-613.

Reid CA, Bekkers JM, Clements JD (1998) N- and P/Q-type Ca ${ }^{2+}$ channels mediate transmitter release with a similar cooperativity at rat hippocampal autapses. J Neurosci 18:2849-2855. 
Robert A, Howe JR (2003) How AMPA receptor desensitization depends on receptor occupancy. J Neurosci 23:847-858.

Rosenmund C, Stern-Bach Y, Stevens CF (1998) The tetrameric structure of a glutamate receptor channel. Science 280:1596-1599.

Sabatini BL, Regehr WG (1997) Control of neurotransmitter release by presynaptic waveform at the granule cell to Purkinje cell synapse. J Neurosci 17:3425-3435.

Schneggenburger R, Neher E (2005) Presynaptic calcium and control of vesicle fusion. Curr Opin Neurobiol 15:266-274.

Silver RA, Lubke J, Sakmann B, Feldmeyer D (2003) High-probability uniquantal transmission at excitatory synapses in barrel cortex. Science 302:1981-1984.

Sims RE, Hartell NA (2005) Differences in transmission properties and susceptibility to long-term depression reveal functional specialization of ascending axon and parallel fiber synapses to Purkinje cells. J Neurosci 25:3246-3257.

Singer JH, Lassova L, Vardi N, Diamond JS (2004) Coordinated multivesicular release at a mammalian ribbon synapse. Nat Neurosci 7:826-833.

Stevens CF (1993) Quantal release of neurotransmitter and long-term potentiation. Cell [Suppl] 72:55-63.

Stevens CF, Wang Y (1995) Facilitation and depression at single central synapses. Neuron 14:795-802.
Tong G, Jahr CE (1994) Multivesicular release from excitatory synapses of cultured hippocampal neurons. Neuron 12:51-59.

Triller A, Korn H (1982) Transmission at a central inhibitory synapse. III. Ultrastructure of physiologically identified and stained terminals. J Neurophysiol 48:708-736.

Ventriglia F, Di Maio V (2003) Stochastic fluctuations of the quantal EPSC amplitude in computer simulated excitatory synapses of hippocampus. Biosystems 71:195-204.

Wadiche JI, Jahr CE (2001) Multivesicular release at climbing fiberPurkinje cell synapses. Neuron 32:301-313.

Watkins JC, Pook PC, Sunter DC, Davies J, Honore T (1990) Experiments with kainate and quisqualate agonists and antagonists in relation to the sub-classification of "non-NMDA" receptors. Adv Exp Med Biol 268:49-55.

Xu-Friedman MA, Regehr WG (2004) Structural contributions to shortterm synaptic plasticity. Physiol Rev 84:69-85.

Xu-Friedman MA, Harris KM, Regehr WG (2001) Three-dimensional comparison of ultrastructural characteristics at depressing and facilitating synapses onto cerebellar Purkinje cells. J Neurosci 21:6666-6672.

Zerangue N, Kavanaugh MP (1996) Flux coupling in a neuronal glutamate transporter. Nature 383:634-637.

Zucker RS, Regehr WG (2002) Short-term synaptic plasticity. Annu Rev Physiol 64:355-405. 